\title{
Development and validation of a size-resolved particle dry deposition scheme for application in aerosol transport models
}

\author{
A. Petroff ${ }^{1, *}$ and L. Zhang ${ }^{1}$ \\ ${ }^{1}$ Air Quality Research Division, Science and Technology Branch, Environment Canada, 4905 Dufferin Street, Toronto, \\ Ontario M3H 5T4, Canada \\ *now at: University of Toronto, Department of Chemistry, 80 St George Street, Toronto, Ontario M5S 3H6, Canada
}

Received: 1 August 2010 - Published in Geosci. Model Dev. Discuss.: 19 August 2010

Revised: 1 December 2010 - Accepted: 3 December 2010 - Published: 23 December 2010

\begin{abstract}
A size-resolved particle dry deposition scheme is developed for inclusion in large-scale air quality and climate models where the size distribution and fate of atmospheric aerosols is of concern. The "resistance" structure is similar to what is proposed by Zhang et al. (2001), while a new "surface" deposition velocity (or surface resistance) is derived by simplification of a one-dimensional aerosol transport model (Petroff et al., 2008b, 2009). Compared to Zhang et al.'s model, the present model accounts for the leaf size, shape and area index as well as the height of the vegetation canopy. Consequently, it is more sensitive to the change of land covers, particularly in the accumulation mode (0.1-1 micron). A drift velocity is included to account for the phoretic effects related to temperature and humidity gradients close to liquid and solid water surfaces. An extended comparison of this model with experimental evidence is performed over typical land covers such as bare ground, grass, coniferous forest, liquid and solid water surfaces and highlights its adequate prediction. The predictions of the present model differ from Zhang et al.'s model in the fine mode, where the latter tends to over-estimate in a significant way the particle deposition, as measured by various investigators or predicted by the present model. The present development is thought to be useful to modellers of the atmospheric aerosol who need an adequate parameterization of aerosol dry removal to the earth surface, described here by 26 land covers. An open source code is available in Fortran90.
\end{abstract}

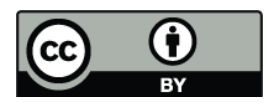

Correspondence to: A. Petroff (alexandre_petroff@yahoo.fr)

\section{Introduction}

Atmospheric aerosols are responsible for increased human mortality and morbidity (Lippmann et al., 2003; Kappos et al., 2004; Englert, 2004), ecosystem acidification and eutrophication (Fowler et al., 2009, and references therein), crop contamination by genetically modified spores (e.g. Jarosz et al., 2004), and for the forcing of the radiative balance of the atmosphere (IPCC, 2007). Their fate in the lower atmosphere is determined by their emission, transformation, transport and removal processes and can be predicted by chemical transport models of pollution or climate models (Gong et al., 2003; Bessagnet et al., 2004; Textor et al., 2006). Depending on the atmospheric and aerosol conditions, removal processes are more or less efficient and aerosol residence time can vary from hours to days (Raes et al., 2000; Williams et al., 2002). Aerosol removal occurs continuously by dry deposition and by wet deposition when it's raining. The relative importance of these two processes depends not only on the local meteorology but also on the aerosol properties (density, size distribution), for example, following yearly based estimates in Nederlands by Erisman et al. (2001), the ratio of dry to total deposition on vegetation can vary between a few percent and somewhere around $40 \%$ for acidifying particles, the latter being obtained over rougher forest. Another study by Zhao et al. (2003) suggested that dry deposition dominates the removal for coarse particles.

Many of the size-dependent dry deposition models apply only to one type of surface such as grass or vegetation canopies (e.g. Davidson et al., 1982; Slinn, 1982) while other models were developed for any type of surface (Sehmel and Hodgson, 1978; Giorgi, 1986; Zhang et al., 2001; Nho-Kim et al., 2004). Comparisons of several models (Ruijgrok et al.,

Published by Copernicus Publications on behalf of the European Geosciences Union. 
1995; Petroff et al., 2008a) revealed that they differ from each other greatly and the largest uncertainty is for the accumulation mode particles (around 0.1-1.0 micron diameter range). In this size range, the predicted deposition velocity $V_{\mathrm{d}}$, defined as the ratio of the particle flux to the concentration at a reference height above the canopy, can vary over two orders of magnitude on vegetation. In fact, most models developed before the 1990s are based on wind-tunnel measurements on low roughness canopies (in particular Chamberlain, 1967) and suggest that particles in the accumulation mode should have deposition velocity $\left(V_{\mathrm{d}}\right)$ values around $0.01 \mathrm{~cm} \mathrm{~s}^{-1}$, which are much smaller values than more recent measurements obtained on rougher canopies such as forests (e.g. Buzorius et al., 2000; Pryor et al., 2007; Grönholm et al., 2009). There, deposition velocity for this size range is about a few tenths of $\mathrm{cm} \mathrm{s}^{-1}$.

Modelling the deposition of aerosol requires to describe the vertical transport of particles by the turbulent flow from the overlaying atmosphere into the canopy, usually through a aerodynamic resistance, and the collection of the particles on the vegetation obstacles (leaves, twigs, trunks, flowers and fruits). Particle collection on obstacles is driven by physical processes of Brownian diffusion, interception, inertial and turbulent impaction, gravitational settling and on water surfaces by phoretic processes as well. These processes are accounted for in the models through efficiencies, that depend on the properties of the vegetation obstacles, the turbulent flow and the depositing aerosol particles (see Petroff et al., 2008a; Pryor et al., 2008, for a model review).

Zhang et al. (2001) developed a size-resolved deposition model based on earlier models (Slinn, 1982; Giorgi, 1986). It describes the main processes of deposition (Brownian diffusion, interception, impaction and sedimentation). The parameterizations of the corresponding efficiencies are optimized by comparison with measurements so the model produces higher $V_{\mathrm{d}}$ values for submicron particles than most earlier models. In general, values between 0.1 and $1 \mathrm{~cm} \mathrm{~s}^{-1}$ are obtained over vegetated surfaces, with higher $V_{\mathrm{d}}$ values over rougher and taller surfaces than over smoother surfaces and higher $V_{\mathrm{d}}$ (especially for large particles) over needleleaf trees than over broadleaf trees.

This model has been adopted by a large number of largescale models around the world (Andersson et al., 2007; Ghan and Easter, 2006; Gong et al., 2006; Heald et al., 2006; Wang et al., 2006; Zakey et al., 2006). Although the model of Zhang et al. (2001) seems to be able to produce more reasonable $V_{\mathrm{d}}$ values for submicron particles compared to many other existing models, the minimum $V_{\mathrm{d}}$ produced by this model is shifted toward larger particle sizes (e.g., 1$2 \mu \mathrm{m}$ ) over several earth surfaces, while earlier models predict this minimum in the accumulation mode (e.g. Slinn, 1982; Davidson et al., 1982). The position of this minimum and whether it is marked or not is open for discussion (Zhang and Vet, 2006; Petroff et al., 2008a; Pryor et al., 2008). One can reasonably assume that it is not constant and should de- pend on the turbulent flow conditions, the particle properties and the dimensions of the surface roughnesses. If experimental evidences are lacking for vegetation canopies, results for water surface (Möller and Schumann, 1970, see Fig. 6 of the present paper) and single fiber deposition (of different diameter and for different wind, see Lee and Liu, 1982) exhibit a minimum deposition velocity varying between 0.1 and 1 micron, smaller than predicted by Zhang et al.'s model.

A new and more sophisticated approach has been developed to model the transport and deposition of aerosol within vegetation composed either of cylindrical obstacles like needles (Petroff et al., 2008b) or of planes obstacles like broadleaves (Petroff et al., 2009). In particular, more information about the canopy morphology are included, such as the leaf area index, the orientation and size distribution of individual leaves, as well as the vertical extension and profile of the canopy crown. This one-dimensional model, hereafter referred to as "1-D-Model", is able to predict the proper particle size for minimum $V_{\mathrm{d}}$ while giving reasonable $V_{\mathrm{d}}$ values over grass and forest. However, this model only applies to vegetation canopies and is numerically too complex and requires too many factors to be implemented in large-scale models.

The present paper deals with the description of an analytical and size-segregated aerosol dry deposition model, which resistive structure is the same as in the model of Zhang et al. (2001), while the improved parameterizations of the surface resistance and the different collection efficiencies are based on previous work (Petroff et al., 2008b, 2009). This model is initially designed for vegetative canopies, but its application is extended in the present paper to 26 land covers (also called Land Use Categories or LUC) used to characterize the earth surface, such as forest, grass, crop, desert, water surface, urban centers. These categories, also used in the gaseous deposition module (Zhang et al., 2003) and the Canadian Global Environmental Multiscale model (GEM, Côté et al., 1998), are based on the land-surface model BATS (Biosphere Atmosphere Transfer Scheme) developed at NCAR by Dickinson et al. (1986) after the archive of Wilson and HendersonSellers (1985). Alternative land cover classifications can be found in Loveland and Belward (1997); Hansen et al. (2000).

\section{Theoretical considerations}

\subsection{Aerodynamic model}

Above the canopy, the inertial sub-layer is assumed to take place right on top of the canopy and can be described by the similarity theory of Monin and Obhukov (1954), eventhough this assumption is questioned in the vicinity of rough canopies. There, the eddy diffusivities for heat and humidity are known to increase significantly compared to the theory in near-neutral to stable atmosphere (Fazu and Schwerdtfeger, 1989; Cellier and Brunet, 1992). The mean flow velocity $U$ 
is classically estimated with the logarithmic law corrected for the stability:

$U(z)=\frac{u_{*}}{\kappa}\left[\ln \left(\frac{z-d}{z_{0}}\right)-\Psi_{\mathrm{m}}\left(\frac{z-d}{L_{\mathrm{O}}}\right)+\Psi_{\mathrm{m}}\left(\frac{z_{0}}{L_{\mathrm{O}}}\right)\right]$,

where $\kappa$ is the von Karman constant, hereafter taken equal to $0.4, z_{0}$ and $d$ are the roughness length and the displacement height of the canopy, $u_{*}$ is the friction velocity above the canopy, $L_{\mathrm{O}}$ is the Obhukov length and $\Psi_{\mathrm{m}}$ the integrated form of the stability function for momentum. In this study, we are using the profiles of Paulson (1970) and Dyer (1974) to describe the stability functions for momentum, heat, as well as their integrated form. Though classical, these formulations are recalled here in order to avoid confusion and inconsistency with the value of $\kappa$. The stability function is given by:

$$
\Psi_{\mathrm{m}}(x)=\left\{\begin{array}{l}
2 \ln \left[\frac{1+(1-16 x)^{\frac{1}{4}}}{2}\right]+\ln \left[\frac{1+(1-16 x)^{\frac{1}{2}}}{2}\right] \\
-2 \operatorname{Arctan}\left[(1-16 x)^{\frac{1}{4}}\right]+\pi / 2 \text { when } x \in[-2 ; 0] \\
-5 x \text { when } x \in[0 ; 1]
\end{array}\right.
$$

The aerosol eddy diffusivity is approached by the eddy diffusivity for heat:

$$
K_{\mathrm{p}}=l_{\mathrm{mp}} u_{*} \quad \text { with } \quad l_{\mathrm{mp}}=\frac{\kappa(z-d)}{\phi_{\mathrm{h}}\left(\frac{z-d}{L_{0}}\right)},
$$

where $l_{\mathrm{mp}}$ is the mixing length for particles and $\phi_{\mathrm{h}}$ is the stability function for heat. Its expression is $\phi_{\mathrm{h}}(x)=(1-$ $16 x)^{-1 / 2}$ when $x \in[-2 ; 0]$ and $\phi_{\mathrm{h}}(x)=1+5 x$ when $x \in$ $[0 ; 1]$. The turbulent Schmidt number is thus taken in Eq. (3) equal to the turbulent Prandtl number. The aerodynamic resistance to the transport of particles between two heights $z_{1}$ and $z_{2}$ above the canopy, is written as:

$R a\left(z_{1}, z_{2}\right)=\frac{1}{\kappa u_{*}}\left[\ln \left(\frac{z_{2}-d}{z_{1}-d}\right)-\Psi_{\mathrm{h}}\left(\frac{z_{2}-d}{L_{\mathrm{O}}}\right)+\Psi_{\mathrm{h}}\left(\frac{z_{1}-d}{L_{\mathrm{O}}}\right)\right]$,

where $\Psi_{\mathrm{h}}$ is the integrated form of the stability function for heat. Its expression is $\Psi_{\mathrm{h}}(x)=2 \ln \left[0.5\left(1+(1-16 x)^{1 / 2}\right)\right]$ when $x \in[-2 ; 0]$ and $\Psi_{\mathrm{h}}(x)=-5 x$ when $x \in[0 ; 1]$. For nonvegetated surfaces, whose roughnesses are not explicitly resolved, the aerodynamic resistance is written as:

$R a\left(z_{0}+d, z_{\mathrm{R}}\right)=\frac{1}{\kappa u_{*}}\left[\ln \left(\frac{z_{\mathrm{R}}-d}{z_{0}}\right)-\Psi_{\mathrm{h}}\left(\frac{z_{\mathrm{R}}-d}{L_{\mathrm{O}}}\right)+\Psi_{\mathrm{h}}\left(\frac{z_{0}}{L_{\mathrm{O}}}\right)\right]$.

Inside the canopy, we use a model based on a diffusive closure of the momentum flux and described by Inoue (1963). It is based on the assumption of constant drag coefficient, mixing length and leaf area density. This model is open to criticism because it assumes a local equilibrium between turbulence production and dissipation within the canopy (Kaimal and Finnigan, 1994). In practice though, such an equilibrium is not reached within the canopy because of the eddy transport term (see for example Brunet et al., 1994). Furthermore, this closure is invalidated by experimental results, that show the existence of secondary maxima of the mean velocity occurring under the foliage crown and corresponding to negative values of the eddy diffusivity (Denmead and Bradley, 1985). In the present study, this rudimentary model is used despite its limitations, because it leads to satisfactory predictions of the aerodynamic properties in the upper part of the canopy. This portion of canopy is of particular interest for aerosol deposition as it corresponds to strong mean flow velocity and local friction velocity and, subsequently, to large deposition fluxes. Using this model to describe the flow and the aerosol transport closer to the ground might be more uncertain (see Grönholm et al., 2009, for particle flux measurements below the crown base of the canopy). This model predicts an exponential decrease of the mean wind velocity $U=\langle u\rangle$, particle eddy diffusivity $K_{\mathrm{p}}$ and local friction velocity $u_{\mathrm{f}}\left(u_{\mathrm{f}}^{2}=-\left\langle u^{\prime \prime} w^{\prime \prime}\right\rangle\right)$. The notation \langle\rangle and " refer, respectively, to the average over time and space and its fluctuations (see Petroff et al., 2008b, for details). As an example, the mean wind velocity is written as:

$U(z)=U_{\mathrm{h}} \exp [\alpha(z / h-1)]$,

where $U_{\mathrm{h}}$ is the horizontal mean flow velocity at the top of the canopy, measured on-site or estimated by Eq. (1), and $\alpha$, the aerodynamic extinction coefficient, is identical for the three properties.

The impact of the atmospheric stability on the aerodynamics within the canopy is not fully understood and an adequate aerodynamic model within the vegetation roughnesses has still to be formulated (see Leclerc et al., 1990; Kaimal and Finnigan, 1994; Lee and Mahrt, 2005, for a study of stability influence on turbulence properties). The recent model of Harman and Finnigan (2007) should be mentioned as an alternative to describe the flow close to and within the roughnesses. Its main advantage is that it explicitly accounts for the extension of the roughness sub-layer above the canopy, but it cannot be used for now in an operational perspective because it strongly depends on the ratio $u_{*} / U_{\mathrm{h}}$, which is highly variable with atmospheric stability.

In the present study, the influence of the stability is taken into account through the modification of aerodynamic properties above the canopy, that is the mixing length $l_{\mathrm{m}}$. Following Inoue (1963), the extinction coefficient is written as:

$\alpha=\left(\frac{c_{\mathrm{d}} k_{x} \mathrm{LAI} h^{2}}{2 l_{\mathrm{m}}^{2}}\right)^{1 / 3}$,

where $k_{x}$ is the inclination coefficient of the canopy elements (see 1-D-model for the values of this parameter for different inclination distribution) and LAI is the two-sided leaf area index. Choosing a constant drag $c_{\mathrm{d}}=1 / 6$ (see the appendix 
of Petroff et al., 2008a, for details) and replacing the mixing length by its value on top of the canopy leads to:

$\alpha=\left(\frac{k_{x} \mathrm{LAI}}{12 \kappa^{2}(1-d / h)^{2}}\right)^{1 / 3} \phi_{\mathrm{m}}^{2 / 3}\left(\frac{h-d}{L_{\mathrm{O}}}\right)$,

where $\phi_{\mathrm{m}}$ is the non-dimensional stability function for momentum, which expression is $\phi_{\mathrm{m}}(x)=(1-16 x)^{-1 / 4}$ when $x \in[-2 ; 0]$ and $\phi_{\mathrm{m}}(x)=1+5 x$ when $x \in[0 ; 1]$. One should notice that the drag coefficient $c_{\mathrm{d}}$ and the displacement height $d$ are assumed not to depend on the stability.

\subsection{Aerosol transport model}

The following assumptions are formulated to describe the canopy-aerosol system. The quasi-stationary state of the flow and the aerosol is reached. Canopy and aerodynamic mean properties are horizontally homogeneous. The canopy is treated solely in terms of the foliage, because its cumulative surface is greater than the surface of other components of the vegetation. Particle deposition in the absence of foliage can easily be studied if the description of the twig system is added to the model.

The aerosol is considered as an homogeneous phase, in which particle-particle interactions, such as agglomeration or fragmentation, as well as particle-gas interactions, such as condensation, evaporation or gas-particle conversion, are not considered. This assumption is open to criticism, as some of these processes are suspected to act at timescales that are comparable to the deposition. In a "hazy case" characterized by a strong condensation growth and moderate agglomeration, Pryor and Binkowski (2004) have showed by numerical means that the time scales associated with condensation of semi-volatile species and inter-modal agglomeration (Aitken- to accumulation modes) can be of the same order of magnitude than the deposition of these modes over a forest. Similarly, studies of the condensation of $\mathrm{NH}_{3}$ and $\mathrm{HNO}_{3}$ gas onto existing aerosol and of the corresponding evaporation of $\mathrm{NH}_{4} \mathrm{NO}_{3}$ droplets have highlighted that these processes can cause the divergence of small particles fluxes above the vegetation (Nemitz and Sutton, 2004; Nemitz et al., 2009). Nevertheless, these processes and the factors affecting their balance are not fully understood and the inclusion of gas/aerosol chemistry and agglomeration in the model is out of reach in the operational context.

The hygroscopicity of particles is accounted for in the similar manner to Zhang et al. (2001). Depending on the aerosol size and chemical composition, as well as the ambient conditions, a wet particle diameter is calculated. Different formulas exist for this purpose in the litterature (Fitzgerald, 1975; Gerber, 1985; Zhang et al., 2005).

Rebound and resuspension of particles are not included in the present model, as it would require an adequate and simple parameterization of these processes and informations that are not available in transport models, such as a description of leaf surface (micro-roughnesses, stickiness, wetness), the relative angle between the particle trajectory and the surface and the wind statistics. Interested readers are referred to Paw U (1983); Paw U and Braaten (1992); Wu et al. (1992a,b); Gillette et al. (2004).

The effects of the gravity and other drift forces such as phoretic effects are taken into account in a similar way as Slinn (1982); Zhang et al. (2001). Following the principle of superposition, their influence is estimated separately through a drift velocity $V_{\text {drift }}$. The deposition resulting from the turbulent transfer and the collection on leaves is estimated in a separate way as well. Both contributions are added and the deposition velocity at the reference height $z_{\mathrm{R}}$ is expressed by:

$$
V_{\mathrm{d}}\left(z_{\mathrm{R}}\right)=V_{\mathrm{drift}}+\frac{1}{R a\left(h, z_{\mathrm{R}}\right)+\frac{1}{V_{\mathrm{ds}}}},
$$

where $V_{\mathrm{ds}}$ is the "surface" deposition velocity calculated on top of the surface roughnesses (its inverse is referred to as the surface resistance). The principle of surperposition is here abused, as gravity (and other drift effects) intervenes both in the transport and the deposition of particles on the vegetation obstacles. Some studies reported that such approach is acceptable for one single obstacle exposed to the deposition of super-micronic particles (Yoshioka et al., 1972, cited by Bache, 1979).

The reference height, where the deposition is calculated, can be chosen as a few times the canopy height for vegetative canopies in order to ensure its position in the inertial sub-layer (for example McMahon and Denison, 1979). However, in chemical transport model, the reference height is often chosen as the lowest resolved altitude, if the model layer is higher than the canopy height. As a rule of thumb, one can choose twice the canopy height for forests or $10 \mathrm{~m}$ for other land covers. The influence of this parameter is only significant for the coarsest particles within the first few canopy heights. Above that, it becomes neglectible (see Petroff, 2005, p. 167).

An approximated relation exists if one needs to recalculate the deposition at a different height.

$$
\frac{1}{V_{\mathrm{d}}\left(z_{2}\right)-V_{\mathrm{drift}}}=\frac{1}{V_{\mathrm{d}}\left(z_{1}\right)-V_{\mathrm{drift}}}+R a\left(z_{1}, z_{2}\right)
$$

This relation, consistent with (Eq. 9), is an approximation of the exact solution:

$$
\frac{V_{\mathrm{drift}}}{V_{\mathrm{d}}\left(z_{2}\right)}-1=\left(\frac{V_{\mathrm{drift}}}{V_{\mathrm{d}}\left(z_{1}\right)}-1\right) e^{-V_{\mathrm{drift}} R a\left(z_{1}, z_{2}\right)}
$$

In case of vegetated surfaces, the aerosol transport is resolved analytically within the canopy (see Sect. 2.2.2). For nonvegetated surfaces such as water surfaces (liquid and solid) as well as deserts and cities, a simplier surface deposition velocity is given in Sect. 2.2.3. 


\subsubsection{Form of the drift velocity}

The drift velocity $V_{\text {drift }}$ is equal to the sedimentation velocity $W_{\mathrm{S}}$ for all surfaces except water, ice and snow surfaces, on which phoretic effects are also included through $V_{\text {phor }}$. These effects are related to important differences of temperature (thermophoresis, see for example Batchelor and Shen, 1985), water vapor (diffusiophoresis per se and Stefan flow effect, Waldman and Schmitt, 1966; Goldsmith and May, 1966) or electricity (Tammet et al., 2001) between the collecting surfaces and the air. These effects can potentially affect the movement of particles. Thermophoresis and diffusiophoresis are expected to have an effect on fine particle deposition on water surfaces (LUC 1, 2, 3 and 23, Table 2). Phoretic effects induce a flux of particles toward cold and evaporating surfaces while the Stefan flow effect induces a flux of particles toward condensating surfaces. The full description of the corresponding balance requires the intensity of these gradients in the immediate vicinity of the surface, which is out of reach in the scope of this simple model. Therefore, we prefer to assign to $V_{\text {phor }}$ a constant small value of $5 \times 10^{-5} \mathrm{~m} \mathrm{~s}^{-1}$ to water and of $2 \times 10^{-4} \mathrm{~m} \mathrm{~s}^{-1}$ to ice and snow surfaces. These values are adjusted on measurements that will be presented later (see Figs. 6 and 7).

The importance of electrophoresis remains uncertain. Tammet et al. (2001) have compared the importance of electrical forces with other mechanical forces for a coniferous forest. They conclude that in typical atmospheric conditions, it might have an impact on the deposition of $0.01-0.2 \mu \mathrm{m}$ particles on the tip of the top needles of trees and under very low-wind conditions, while effects might be sheltered within the canopy. It is presently unclear how this process might affect the deposition on the canopy as a whole. Thus, we prefer not to account for it in the parameterization of the drift velocity. In the present study, the latter is expressed by:

$V_{\text {drift }}=W_{\mathrm{S}}+V_{\text {phor }}$,

with $V_{\text {phor }}=5 \times 10^{-5} \mathrm{~m} \mathrm{~s}^{-1}$ for LUC $1,3,23, V_{\text {phor }}=2 \times$ $10^{-4} \mathrm{~m} \mathrm{~s}^{-1}$ for LUC 2 and $V_{\text {phor }}=0$ elsewhere.

\subsubsection{Derivation of the surface deposition velocity for vegetated surfaces}

Let $\gamma$ be the aerosol mass concentration density averaged on time and space. Within the canopy, its balance equation is written as:

$\frac{\mathrm{d}}{\mathrm{d} z}\left[K_{\mathrm{p}} \frac{\mathrm{d}\langle\gamma\rangle}{\mathrm{d} z}\right]=a\langle\gamma\rangle V_{\mathrm{T}}$,

where $a$ is the two-sided leaf area density and $V_{\mathrm{T}}$ is the total collection velocity on vegetation. Based on previous work, $V_{\mathrm{T}}$ can be written as:

$V_{\mathrm{T}}(z)=E_{\mathrm{T}}(z) u_{\mathrm{f}}(z) \quad$ with

$E_{\mathrm{T}}=\frac{U_{\mathrm{h}}}{u_{*}}\left(E_{\mathrm{B}}+E_{\mathrm{IN}}+E_{\mathrm{IM}}\right)+E_{\mathrm{IT}}$,
Table 1. Parameterization of the deposition efficiencies over vegetation.

\begin{tabular}{lcc}
\hline Process & Needle-like obstacles & leaf or plane obstacles \\
\hline Brownian diffusion & \multicolumn{1}{c}{$C_{\mathrm{B}} S c^{-2 / 3} R e_{\mathrm{h}}^{-1 / 2}$} \\
Interception & $C_{\mathrm{IN}} \frac{d_{\mathrm{p}}}{L}$ & $C_{\mathrm{IN}} \frac{d p}{L}\left[2+\ln \frac{4 L}{d_{\mathrm{p}}}\right]$ \\
Inertial impaction & $C_{\mathrm{IM}}\left[\frac{S t_{\mathrm{h}}}{S t_{\mathrm{h}}+\beta_{\mathrm{IM}}}\right]^{2}$ \\
Turbulent impaction & $2.5 \times 10^{-3} C_{\mathrm{IT}} \tau_{\mathrm{ph}}^{+2} \quad$ if $\quad \tau_{\mathrm{ph}}^{+}<20$ \\
& $C_{\mathrm{IT}}$ & if $\tau_{\mathrm{ph}}^{+} \geq 20$ \\
\hline
\end{tabular}

Where $E_{\mathrm{T}}$ is the total collection efficiency, and $E_{\mathrm{B}}, E_{\mathrm{IN}}$, $E_{\mathrm{IM}}$ and $E_{\mathrm{IT}}$ are the collection efficiencies corresponding to Brownian diffusion, interception, inertial impaction and turbulent impaction. In theory, these efficiencies depend on the altitude (1-D-model) but, in the present study, they are considered to have a constant value, estimated on top of the canopy (see Table 1). In order to minimize the errors induced by this simplification, the numerical coefficients appearing in the efficiency formulation are adjusted with help of the 1-Dmodel. This fitting procedure is detailed in Sect. 2.2.5.

Considering constant efficiencies throughout the canopy allows us to derive an analytical solution to the mass balance (Eq. 13). Introducing the non-dimensional height $z^{+}=z / h$ and concentration $\gamma^{+}=\gamma(z) / \gamma(h)$ and accounting for the exponential profile of $K_{\mathrm{p}}$ (similar to Eq. 6), the mass balance (Eq. 13) can be rewritten as:

$$
\frac{\mathrm{d}^{2} \gamma^{+}}{\mathrm{d} z^{+2}}+\alpha \frac{\mathrm{d} \gamma^{+}}{\mathrm{d} z^{+}}-Q \gamma^{+}=0 \quad \text { with } \quad Q=\frac{h \cdot \text { LAI } . V_{\mathrm{T}}}{K_{\mathrm{p}}} .
$$

The non-dimensional number $Q$ (as notated by Fernandez de la Mora and Friedlander, 1982) corresponds to the ratio of the turbulent transport time scale to the vegetation collection time scale. Typically, $Q \ll 1$ corresponds to a situation of a very efficient turbulent mixing while the transfer of particle is limited by the collection efficiency on leaves. This means an homogeneous concentration throughout the canopy, as it can be observed for Aitken and accumulation mode particles. Meanwhile, $Q \gg 1$ corresponds to a situation where particles are so efficiently collected by leaves that their transfer to the surfaces is rather limited by the turbulent transport. It means an inhomogeneous particle concentration within the canopy, as it can be observed for coarse mode particles. It can be rewritten as:

$Q=\mathrm{LAI} E_{\mathrm{T}} h / l_{\mathrm{mp}}(h)$.

A boundary condition is required on the lower part of the canopy to describe the particle transfer to the ground. There, 
the flux is related to the concentration near the surface $\gamma^{+}(0)$ by a ground deposition velocity $V_{\mathrm{g}}$ :

$\frac{\mathrm{d} \gamma^{+}}{\mathrm{d} z^{+}}(0)=Q_{\mathrm{g}} \gamma^{+}(0) \quad$ with $\quad Q_{\mathrm{g}}=\frac{h V_{\mathrm{g}}}{K_{\mathrm{p} 0}}$

where $Q_{\mathrm{g}}$ is the analog of $Q$ for the transfer to the ground, and $K_{\mathrm{p} 0}$ is the value of the particle eddy diffusivity at its vicinity. The ground deposition velocity is related to the ground deposition efficiency by $V_{\mathrm{g}}=E_{\mathrm{g}} u_{\mathrm{f}}(0)$. The formulation of $E_{\mathrm{g}}$ is based on the assumption of smooth ground and is given in Sect. 2.2.4. The non-dimensional number $Q_{\mathrm{g}}$ can be rewritten as:

$Q_{\mathrm{g}}=E_{\mathrm{g}} h / l_{\mathrm{mp}}(h)$.

One should note the strong similarities between the nondimensional numbers $Q$ and $Q_{\mathrm{g}}$, and that the amount of leaves available for deposition, i.e. LAI, is explicitly appearing in the formulation of $Q$ (Eq. 16). Assuming that the collection efficiencies, and thus $Q$ and $Q_{\mathrm{g}}$, are constant allows us to derive an analytical solution for the particle concentration:

$\gamma^{+}=\mathrm{e}^{\alpha / 2\left(1-z^{+}\right)}\left[\frac{\eta \cosh \left(\eta z^{+}\right)+\left(Q_{\mathrm{g}}+\alpha / 2\right) \sinh \left(\eta z^{+}\right)}{\eta \cosh (\eta)+\left(Q_{\mathrm{g}}+\alpha / 2\right) \sinh (\eta)}\right]$

with $\eta=\sqrt{\alpha^{2} / 4+Q}$.

The deposition velocity on top of the canopy, i.e. the surface deposition velocity, corresponds to the ratio of the depositing flux on the canopy to the concentration on top of the canopy. It can be expressed as:

$V_{\mathrm{ds}} / u_{*}=V_{\mathrm{g}} / u_{*} \gamma_{0}^{+}+\mathrm{LAI} E_{\mathrm{T}} \int_{0}^{1} \gamma^{+} \mathrm{e}^{\alpha\left(z^{+}-1\right)} \mathrm{d} z^{+}$.

After some algebra, its formulation becomes:

$\frac{V_{\mathrm{ds}}}{u_{*}}=E_{\mathrm{g}} \frac{1+\left[\frac{Q}{Q_{\mathrm{g}}}-\frac{\alpha}{2}\right] \frac{\tanh (\eta)}{\eta}}{1+\left[Q_{\mathrm{g}}+\frac{\alpha}{2}\right] \frac{\tanh (\eta)}{\eta}}$

The Eq. (21) expresses the dependency of the surface deposition velocity on characteristics of the vegetation, the aerodynamics and the aerosol. One can thus wonder what would be the limit of the expression when the vegetation vanishes, i.e. when LAI $\rightarrow 0$ while $d / h \rightarrow 0$ (as prescribed by Raupach, $1994,1995)$. In this case, $\alpha \rightarrow 0, \eta \rightarrow 0$ and $\tanh (\eta) / \eta \rightarrow 1$. As a consequence, $V_{\mathrm{ds}} / u_{*} \rightarrow E_{\mathrm{g}} /\left(1+Q_{\mathrm{g}}\right)$ and the deposition velocity above the canopy is such that:

$1 /\left(V_{\mathrm{d}}-V_{\text {drift }}\right) \rightarrow 1 /\left(E_{\mathrm{g}} u_{*}\right)+h /\left(u_{*} l_{\mathrm{mp}}(h)\right)+R a\left(h, z_{\mathrm{R}}\right)$.

The second term on the right-hand side corresponds to the integration of $1 / K_{\mathrm{p}}$ over $[0, h]$ when $\alpha=0$, and is equal to $R a(0, h)$ (or $R a\left(z_{0}, h\right)$ if we account for the roughness of the ground).
As a consequence, $1 /\left(V_{\mathrm{d}}-V_{\text {drift }}\right) \rightarrow 1 /\left(u_{*} E_{\mathrm{g}}\right)+$ $R a\left(z_{0}, z_{\mathrm{R}}\right)$, which is conform to the expectation that the surface deposition velocity for bare ground is driven by the deposition efficiency on the ground and the aerodynamic resistance.

\subsubsection{Surface deposition velocity for non-vegetated surfaces}

By extension of the asymptotic limit of Eq. (21) without vegetation, the deposition velocity for non-vegetated surfaces (liquid or solid water surfaces and desert) is simply:

$V_{\mathrm{d}}\left(z_{\mathrm{R}}\right)=V_{\mathrm{drift}}+\frac{1}{R a\left(z_{0}, z_{\mathrm{R}}\right)+1 /\left(E_{\mathrm{g}} u_{*}\right)}$

where the expression of $E_{\mathrm{g}}$ is detailed hereafter.

\subsubsection{Parameterization of the ground deposition}

The aerosol deposition on the ground below the vegetation canopy takes into account the Brownian diffusion and the turbulent impaction. Their deposition efficiencies, respectively $E_{\mathrm{gb}}$ and $E_{\mathrm{gt}}$, are based on theoretical and empirical results obtained for turbulent flow in pipes (see for example Davies, 1966; Papavergos and Hedley, 1984). The Brownian diffusion efficiency is expressed as:

$E_{\mathrm{gb}}=\frac{S c^{-2 / 3}}{14.5}\left[\frac{1}{6} \ln \frac{(1+F)^{2}}{1-F+F^{2}}+\frac{1}{\sqrt{3}} \operatorname{Arctan} \frac{2 F-1}{\sqrt{3}}+\frac{\pi}{6 \sqrt{3}}\right]^{-1}$,

where $F$ is a function of the Schmidt number expressed as $F=S c^{1 / 3} / 2.9$. An approximation of Eq. (24) given by Wood (1981) has been used by Petroff et al. (2009). However in the present study we prefer to use the original formulation rather than the simplification proposed by Wood, because the latter leads to significant errors for nano-particles: At $20^{\circ} \mathrm{C}$, the relative error is about $60 \%$ for $1 \mathrm{~nm}$ particles while it falls to about $5 \%$ for $14 \mathrm{~nm}$ particles.

The turbulent impaction efficiency term is similar to the one used to model deposition on vegetation (see Table 1) but is expressed on the ground, i.e. for a local friction velocity of $u_{\mathrm{f}}=u_{*} e^{-\alpha}$. The constant $C_{\mathrm{IT}}$ is taken as 0.14 . The latter is slightly different than previous work $(0.18)$ but ensures the continuity of $E_{\mathrm{IT}}$ when $\tau_{\mathrm{p}}^{+}=20$. This change does not affect the results of the 1-D-model in a significant way.

\subsubsection{Parameterization of the collection efficiencies on leaves}

The efficiencies with which physical processes intervene in aerosol deposition depend on the shape, dimensions and orientation of the elemental obstacles (leaf or needle). In the 
operational perspective, where such morphological and statistical details are out of reach, these dependencies are simplified in the following ways. The characteristic length $L$ of the canopy obstacles is taken as the diameter for needles and as the mean width for leaves. It follows a Dirac distribution i.e. each obstacle has the same size. A uniform distribution is assumed for the azimut angle. The inclination distribution is chosen as vertical for short grass, as erectophile for long grass and all crop species, while forests and shrubs are described by the plagiophile distribution. Boundary-layers around obstacles are assumed to be laminar. The corresponding formulations of the efficiencies are based on the 1-Dmodel. They are briefly restated in Table 1 , where $S c$ is the Schmidt number $\left(S c=v_{\mathrm{a}} / D_{\mathrm{B}}, D_{\mathrm{B}}\right.$ being the coefficient of Brownian diffusion and $v_{\mathrm{a}}$ air kinematic viscosity), $R e_{\mathrm{h}}$ is the Reynolds number of the flow estimated on top of the canopy $\left(R e_{\mathrm{h}}=U_{\mathrm{h}} L / v_{\mathrm{a}}, S t_{h}\right.$ is the Stokes number on top of the canopy $\left(S t_{\mathrm{h}}=\tau_{\mathrm{p}} U_{\mathrm{h}} / L\right.$, with $\tau_{\mathrm{p}}$ the relaxation time of the particle), $\tau_{\mathrm{ph}}^{+}$is the non-dimensional relaxation time of the particle on top of the canopy $\left(\tau_{\mathrm{ph}}^{+}=\tau_{\mathrm{p}} u_{*}^{2} / \nu_{\mathrm{a}}\right)$.

In theory, the constants $C_{\mathrm{B}}, C_{\mathrm{IN}}, C_{\mathrm{IM}}$ and $C_{\mathrm{IT}}$ appearing in Table 1 account for the chosen distributions of characteristic length and orientation of the obstacles. But in the present model, the efficiencies are taken constant throughout the canopy and the different constants have to be adjusted for each vegetated surfaces.

To do so, in a first step, probable variation ranges are defined for the main parameters of the two models, namely the friction velocity ( 3 values), the obstacle dimension $(2$ values), the ratios $z_{0} / h(0.05-0.1)$ and $d / h(0.65-0.85)$, LAI ( 2 values), particle density $\left(1000-3000 \mathrm{~kg} \mathrm{~m}^{-3}\right)$ and the ratio of the foliage base height to the canopy heights ( 2 values, only for forest and shrubs). The combinations of these parameters gives us between 96 and 192 configurations. In a second step, the present model and the 1-Dmodel are run side by side under each of these configurations for particle size between $1 \mathrm{~nm}$ and $1 \mathrm{~mm}$. The relative error between them, Err, is used to estimate their agreement: $\mathrm{Err}=\left(V_{\mathrm{d}}(1\right.$-Dmodel $)-V_{\mathrm{d}}($ present $\left.)\right) / V_{\mathrm{d}}(1-\mathrm{D}$-model $)$. Multiple values of the coefficients $C_{\mathrm{B}}, C_{\mathrm{IN}}, C_{\mathrm{IM}}$ and $C_{\mathrm{IT}}$ are used to run the present model until the relative error with the 1-Dmodel is minimized over the entire size range.

Such a fitting exercise is required for two reasons. The first is that the derivation of the present model assumes constant particle deposition efficiencies. The second reason is that the present model treats the vegetation surface as vertically uniform. This assumption induces biases with the 1-D-model in canopies such as forest, in which vegetation is concentrated in the upper-part of the canopy where the wind is strong. The values of $C_{\mathrm{B}}, C_{\mathrm{IN}}, C_{\mathrm{IM}}$ and $C_{\mathrm{IT}}$ resulting from this fitting procedure are given in Table 2.

In order to control the quality of the fit of the different constants, we consider the land cover 14 , i.e. long grass, and we study the contributions of the different processes to the total deposition predicted by the present model (see Fig. 1). The relative error between the present model and the 1-D-model is also given, when processes are considered separately or together (see Fig. 1, right hand side).

Under low wind, the deposition of particle is driven by Brownian diffusion, interception and sedimentation (see Fig. 1a). There, one can notice an under-estimation of the present model for coarse particles that is due to the treatment of the gravity. In the present model, sedimentation is considered independently of the amount of vegetation surfaces and their orientation, while in the 1-D-model, the sedimentation is considered as a collection mechanism both on the leaves and the canopy ground. As a result, the sedimentation is under-estimated in the present model. As the wind increases, this effect vanishes because sedimentation is not the sole dominant process anymore in this size range and that other effects related to particle inertia (inertial and turbulent impactions) become important too (see Fig. 1d). The relative error between the two models, when only one process is activated, can be significant, in particular for inertial effects on fine particles. However, this gap does not have an impact on the overall prediction, because these processes are not dominant in this particular size range. In general, the relative error remains smaller than $30 \%$, which confirms the quality of the fit.

\subsubsection{Other parameters of the Land Use Categories}

The other parameters describing the LUC are the mean height of the canopy $h$, the roughness length $z_{0}$ and the displacement height $d$, the two-sided leaf area index LAI and the characteristic obstacle length $L$. They are given in Table 2. The values of the roughness length and the leaf area index are given by Zhang et al. (2003). The LAI reported in Table 2 is twice the value given by Zhang et al., because they work with one-sided LAI. Details about the seasonal variation of $z_{0}$ and LAI are given by Zhang et al. (2003), in particular their Fig. 2 and Eq. (11). The values of canopy height and displacement are calculated based on the roughness length (Raupach et al., 1991): $z_{0} / h=0.06$ and $d / h=0.80$ for forests (LUC 4 to 9 and 25, 26), where the maximum value of $z_{0}$ is used in the case of deciduous forest, $z_{0} / h=0.13$ and $d / h=0.64$ for shrubs (LUC 10 to 12) where the maximum value of $z_{0}$ is used in the case of deciduous shrubs; and $z_{0} / h=0.13$ and $d / h=0.64$ in the case of crops, grass, tundra, swamp (LUC 13 to 20 and 22, 23 ), where the canopy height is allowed to increase with the roughness length. The characteristic lengths of leaves and needles are estimates for each type of vegetation. The urban environment (LUC 21) is treated like in the global environmental multiscale (GEM) with the LAI of 2 and the assumption that the urban trees are a mixture of needleand broadleaf trees. This description is open to criticism, as the building themselves are not represented and the local heterogeneities likely influence the aerosol fate between 
(a) $V_{d}$ at $u_{*}=10 \mathrm{~cm} \cdot \mathrm{s}^{-1}$

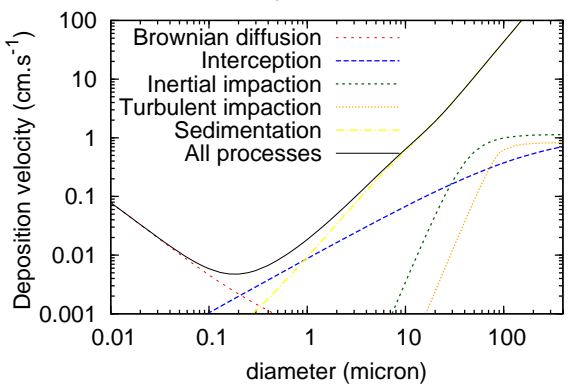

(c) $V_{d}$ at $u_{*}=90 \mathrm{~cm} \cdot \mathrm{s}^{-1}$

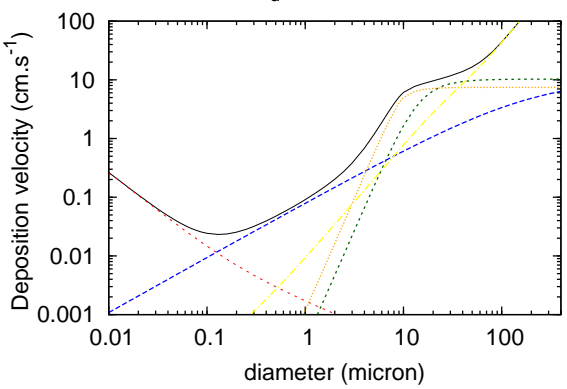

(b) Err at $\mathrm{u}_{*}=10 \mathrm{~cm} \cdot \mathrm{s}^{-1}$

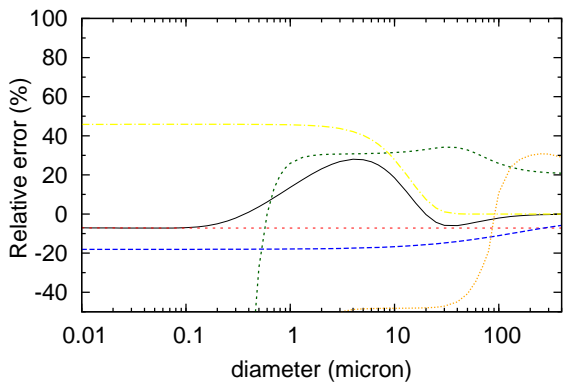

(d) Err at $u_{*}=90 \mathrm{~cm} \cdot \mathrm{s}^{-1}$

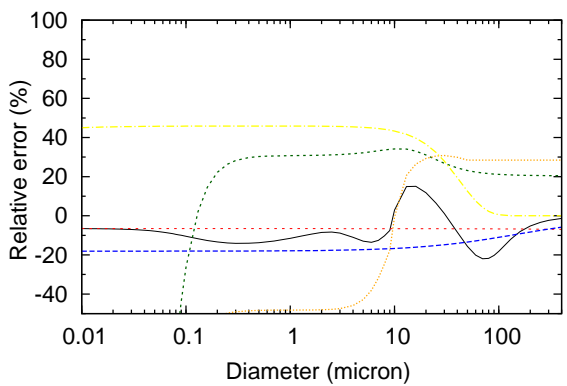

Fig. 1. Deposition on long grass (LUC 14) and influence of the different processes under low and wind high conditions $\left(u_{*}=10\right.$ and $\left.90 \mathrm{~cm} \mathrm{~s}^{-1}\right)$. The canopy is characterized by $h=0.77 \mathrm{~m}, \mathrm{LAI}=4, z_{0}=0.1 \mathrm{~m}$ and $d=0.49 \mathrm{~m}$, while $\rho_{\mathrm{p}}=1500 \mathrm{~kg} \mathrm{~m}^{-3}$. The deposition velocity at $z_{\mathrm{R}}=5 \mathrm{~m}$, predicted by the present model, is given on the left hand side. The relative error Err between the present model and the 1-D-model is given on the right hand side, when the different processes are considered separately or together.

Table 2. Coefficients for different Land Use Categories (LUC). The obstacle shape chosen to represent the LUC is given in brackets as N for needle and L for leaf or plane obstacles. (*) For the mixed wood forest and transitional forest, the deposition velocity for the evergreen needleleaf forest (LUC 4) and for the deciduous broadleaf forest (LUC 7) are calculated and the resulting deposition velocity for the mixed wood forest and the transitional forest is estimated as the average weighted by the proportion of tree types.

\begin{tabular}{|c|c|c|c|c|c|c|c|c|c|c|c|}
\hline & LUC & $h(\mathrm{~m})$ & $z_{0}(\mathrm{~m})$ & $d(\mathrm{~m})$ & LAI 2-sides & $L(\mathrm{~cm})$ & $C_{\mathrm{B}}$ & $C_{\mathrm{IN}}$ & $C_{\mathrm{IM}}$ & $\beta_{\mathrm{IM}}$ & $C_{\mathrm{IT}}$ \\
\hline 1 & water & - & $\mathrm{f}(\mathrm{u})$ & 0. & - & - & - & - & - & - & - \\
\hline 2 & ice & - & 0.01 & 0. & - & - & - & - & - & - & - \\
\hline 3 & inland lake & - & $\mathrm{f}(\mathrm{u})$ & 0. & - & - & - & - & - & - & - \\
\hline 4 & evergreen needleleaf $(\mathrm{N})$ & 15. & 0.9 & 12. & 10. & 0.15 & 0.887 & 0.810 & 0.162 & 0.60 & 0. \\
\hline 5 & evergreen broadleaf (L) & 33.33 & 2. & 26.67 & 12. & 4 & 1.262 & 0.216 & 0.130 & 0.47 & 0.056 \\
\hline 6 & deciduous needleleaf $(\mathrm{N})$ & 15. & $0.4-0.9$ & 12. & $0.2-10$ & 0.15 & 0.887 & 0.810 & 0.162 & 0.60 & 0. \\
\hline 7 & deciduous broadleaf $(\mathrm{L})$ & 16.67 & $0.4-1$ & 13.33 & $0.2-10$ & 3 & 1.262 & 0.216 & 0.130 & 0.47 & 0.056 \\
\hline 8 & tropical broadleaf $(\mathrm{L})$ & 41.67 & 2.5 & 33.33 & 12 & 4 & 1.262 & 0.216 & 0.130 & 0.47 & 0.056 \\
\hline 9 & drought deciduous forest $(\mathrm{L})$ & 16.67 & 0.6 & 13.33 & 8 & 3 & 1.262 & 0.216 & 0.130 & 0.47 & 0.056 \\
\hline 10 & evergreen broadleaf shrubs (L) & 1.54 & 0.2 & 0.98 & 6 & 2 & 0.930 & 0.140 & 0.086 & 0.47 & 0.014 \\
\hline 11 & deciduous shrubs $(\mathrm{L})$ & 1.54 & $0.05-0.2$ & 0.98 & $1-6$ & 2 & 0.930 & 0.140 & 0.086 & 0.47 & 0.014 \\
\hline 12 & thorn shrubs $(\mathrm{L})$ & 1.54 & 0.2 & 0.98 & 6 & 2 & 0.930 & 0.140 & 0.086 & 0.47 & 0.014 \\
\hline 13 & short grass and forbs (N/L) & 0.31 & 0.04 & 0.20 & 2 & 0.5 & $0.700 / 0.996$ & $0.700 / 0.191$ & $0.191 / 0.191$ & $0.60 / 0.47$ & $0.042 / 0.042$ \\
\hline 14 & long grass $(\mathrm{L})$ & $0.15-0.77$ & $0.02-0.10$ & $0.10-0.49$ & $1-4$ & 1 & 0.996 & 0.162 & 0.081 & 0.47 & 0.056 \\
\hline 15 & crops $(\mathrm{L})$ & $0.15-0.77$ & $0.02-0.10$ & $0.10-0.49$ & $0.2-8$ & 3 & 0.996 & 0.162 & 0.081 & 0.47 & 0.056 \\
\hline 16 & rice $(\mathrm{L})$ & $0.15-0.77$ & $0.02-0.10$ & $0.10-0.49$ & $0.2-12$ & 2 & 0.996 & 0.162 & 0.081 & 0.47 & 0.056 \\
\hline 17 & sugar $(\mathrm{L})$ & $0.15-0.77$ & $0.02-0.10$ & $0.10-0.49$ & $0.2-10$ & 4 & 0.996 & 0.162 & 0.081 & 0.47 & 0.056 \\
\hline 18 & maize $(\mathrm{L})$ & $0.15-0.77$ & $0.02-0.10$ & $0.10-0.49$ & $0.2-8$ & 5 & 0.996 & 0.162 & 0.081 & 0.47 & 0.056 \\
\hline 19 & cotton $(\mathrm{L})$ & $0.15-1.54$ & $0.02-0.2$ & $0.10-0.98$ & $0.2-10$ & 7 & 0.996 & 0.162 & 0.081 & 0.47 & 0.056 \\
\hline 20 & irrigated crops (L) & 0.38 & 0.05 & 0.25 & 10 & 3 & 0.996 & 0.162 & 0.081 & 0.47 & 0.056 \\
\hline 21 & urban (N/L) & 17 & 1. & 11.90 & 1. & $0.15 / 3$ & $0.887 / 1.262$ & $0.810 / 0.216$ & $0.162 / 0.130$ & $0.60 / 0.47$ & $0 . / 0.056$ \\
\hline 22 & tundra $(\mathrm{N})$ & 0.23 & 0.03 & 0.14 & $0.2-4$ & 0.5 & 0.700 & 0.700 & 0.191 & 0.60 & 0.042 \\
\hline 23 & swamp (L) & 0.77 & 0.1 & 0.49 & 8 & $0.2-4$ & 0.996 & 0.162 & 0.081 & 0.47 & 0.056 \\
\hline 24 & desert & - & 0.04 & - & 0. & - & - & - & - & - & - \\
\hline 25 & mixed wood forest $(*)(\mathrm{N} / \mathrm{L})$ & 15 & $0.6-0.9$ & 12 & $6-10$ & $0.15 / 3$ & $0.887 / 1.262$ & $0.810 / 0.216$ & $0.162 / 0.130$ & $0.60 / 0.47$ & $0 . / 0.056$ \\
\hline 26 & transitional forest $(*)(\mathrm{N} / \mathrm{L})$ & 15 & $0.6-0.9$ & 12 & $6-10$ & $0.15 / 3$ & $0.887 / 1.262$ & $0.810 / 0.216$ & $0.162 / 0.130$ & $0.60 / 0.47$ & $0 . / 0.056$ \\
\hline
\end{tabular}


the buildings. The assumption here is that particle deposition is only significant over extended vegetation areas such as parks and that at the city scale, particle emission, accounted for in another module of the chemical transport model, is significantly dominating the aerosol balance (see the measurements by Dorsey et al., 2002; Mårtensson et al., 2006; Schmidt and Klemm, 2008).

\section{Results}

Results of the present model are evaluated in the following manner. First, its results are compared with the results of the 1-D-model on two typical vegetated canopies, in order to ensure the quality of the fit. Secondly, its results are compared to measurements obtained for different earth surfaces, such as desert, short grass, coniferous forest and water, both in liquid and solid phases as well as results produced by the model of Zhang et al. (2001). Unless otherwise stated, the aerosol density is chosen as $\rho_{\mathrm{p}}=1500 \mathrm{~kg} \mathrm{~m}^{-3}$.

It is worth mentioning at this point the main differences between the present model and Zhang et al.'s model: First, the formulation of the surface deposition velocity is different and the present model accounts for more morphological characteristics of the canopy such as the leaf area index LAI and the canopy height. The sensitivity to surface change is thus expected to be larger in the present model. Secondly, the same processes are considered here and in Zhang et al.'s model, except the rebound, not accounted for in the present model and the turbulent impaction, accounted here but not in Zhang et al.'s model. For processes described in both models, the parameterization is significantly different (see for example the Brownian diffusion). Thirdly, in the present model, the ground is explicitly accounted for as a deposition surface of the land cover. As a result, bare ground appears as an asymptotic case when the canopy vegetation vanishes.

\subsection{Evaluation of the fit on two vegetation covers}

Two typical vegetation covers of short grass (LUC 13) and coniferous forest (LUC 4) are chosen to compare in Fig. 2 the present model and the 1-D-model. The relative error is used as an indicator of agreement and different wind conditions are explored.

On these vegetation covers, the relative error stays confined between -30 and $25 \%$. One should notice that it returns to 0 when the particle diameter increases and that the sedimentation dominates the deposition.

The difference of treatement of the gravity appears for the coniferous forest under very light wind conditions (see Fig. 2d). There, the visible under-estimation of the aggretated model for particle between 1 and $10 \mu \mathrm{m}$ is related to the fact that the inclinated leaves (plagiophile distribution) collect particles by gravity in the 1-D-Model. Meanwhile, the present model does not account for sedimentation as a col- lection mechanism on the vegetation per se, but rather considers it as a process of deposition on the overall surface. For stronger wind, this bias disappears quickly.

\subsection{Deposition on bare soil}

We rely on experimental measurements of deposition on a smooth horizontal surface (Sehmel, 1973) to assess the validity of the parameterization of the ground deposition and evaluate the present model on bare soil/desert (Eq. 23). The Fig. 3 presents the evolution of the deposition velocity at $z_{\mathrm{R}}=1 \mathrm{~m}$ with particle diameter for three different flow conditions. Results of Zhang et al.'s model are also included on Fig. 3.

Under conditions of low wind $\left(u_{*}=11 \mathrm{~cm} \mathrm{~s}^{-1}\right)$, the deposition of coarse particles is strictly driven by the effect of gravity and both models reproduce this effect properly and stick to the curve of sedimentation. As the friction velocity increases, inertial effects are taking place for particles larger than 2 microns, which are correctly accounted for in both models (by a maximum factor of 2). Larger differences between models arise in the accumulation mode, where the present model reproduces adequately these measurements while Zhang et al's model over-estimates them by one to two orders of magnitude. The reason of this broad difference between models lies in the parameterization of the Brownian diffusion, in particular a difference of one order magnitude in the numerical constant and of one tenth in the Schmidt number exponent.

One can also notice on Fig. 3 the impact of the surface stickiness on the deposition of the coarsest particles by strong wind (last point of the data set corresponding to $d_{\mathrm{p}}=30 \mu \mathrm{m}$ ). The rebound, not accounted for in the present model, induces an over-estimation of a factor 4 .

It is important to mention that real bare ground differs from this ideal smooth situation in which the measurements have been performed. The increase of roughness related to the topography and the presence of bulk obstacles like rocks or isolated plants most likely will perturbate the flow and the deposition pattern. More measurements are needed to estimate the expected increase in the deposition velocity of fine particles and improve the parameterization of the ground deposition.

\subsection{Deposition on short grass}

Experiments performed on short grass (Chamberlain, 1967; Clough, 1975; Garland, 1983) and moorland (Gallagher et al., 1988; Nemitz et al., 2002) are used to evaluate the performance of the present model fed with the parameters of LUC 13 (Tables 1 and 2). The two possible shapes of obstacle (plane or cylindrical) are investigated. The present model, the 1-D-model and the model of Zhang et al. (2001) are run for a friction velocity of $u_{*}=40 \mathrm{~cm} \mathrm{~s}^{-1}$, which corresponds to the average friction velocity reported in the measurements 

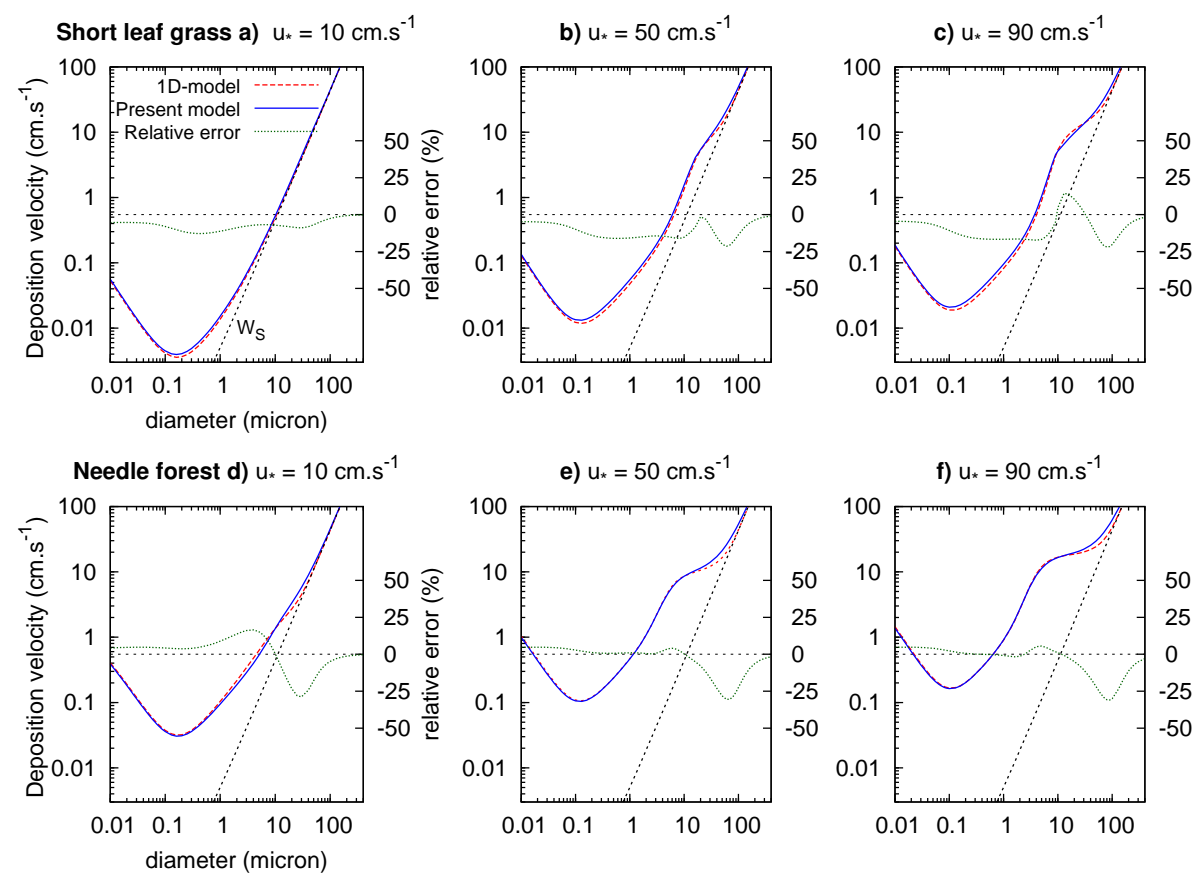

Fig. 2. Comparison of the present model and the 1-D-model under configurations of evergreen needleleaf forest (LUC 4) and short grass (LUC 13, with leaves) for different friction velocity conditions. For the 1-D-model, the crown base height of the forest is taken as $h / 2$ and the vertical profile of the leaf surface density as gaussian. Other parameters are given in Table 2. Blue and red plain lines correspond respectively to the present model and the the 1-D-model, while the green plain line corresponds to the relative error between them. The black line corresponds to the sedimentation velocity.

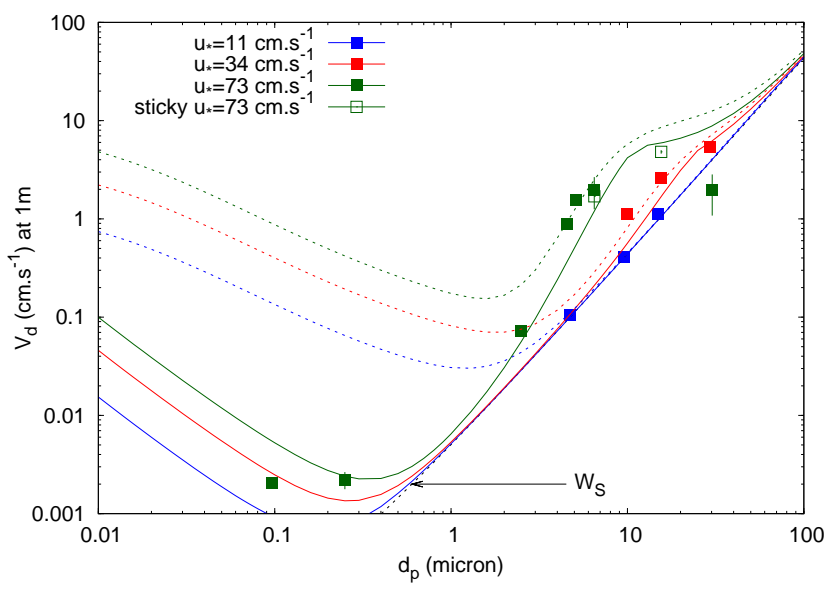

Fig. 3. Deposition on smooth soil, as measured through its mean and standard deviation by Sehmel (1973) and predicted by the present model and the model of Zhang et al. (2001), respectively in plain and dashed lines, for friction velocities of $11 \mathrm{~cm} \mathrm{~s}^{-1}$ (blue), $34 \mathrm{~cm} \mathrm{~s}^{-1}$ (red), $74 \mathrm{~cm} \mathrm{~s}^{-1}$ (green).

$\left(u_{*} \in\left[25 ; 55 \mathrm{~cm} \mathrm{~s}^{-1}\right]\right)$. The atmosphere is assumed to be in near-neutral condition. A common height of $3.8 \mathrm{~m}$ is used to recalculate the deposition velocity (Eq. 10). Results are presented on Fig. 4.

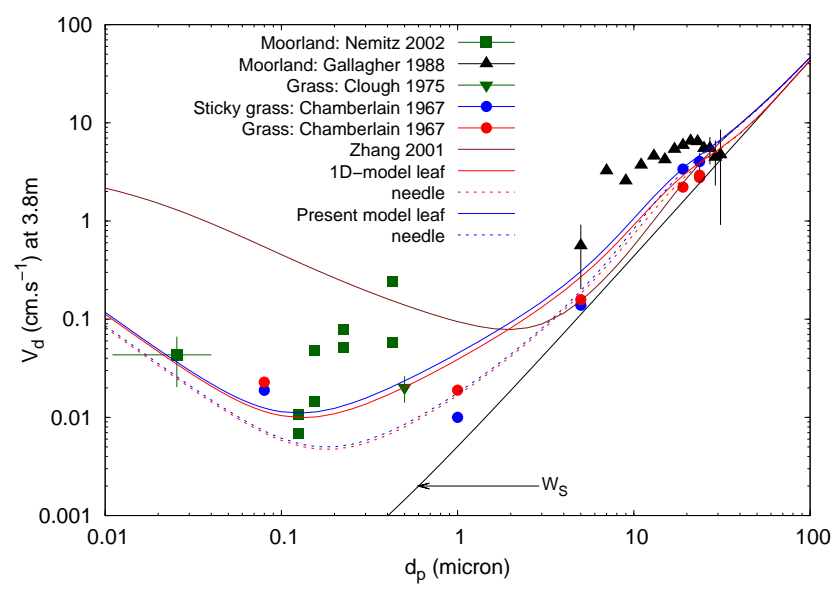

Fig. 4. Deposition on grass, as measured by Chamberlain (1967); Clough (1975); Garland (1983); Gallagher et al. (1988); Nemitz et al. (2002) for friction velocity between 25 and $55 \mathrm{~cm} \mathrm{~s}^{-1}$. A friction velocity of $40 \mathrm{~cm} \mathrm{~s}^{-1}$ is used to run the model of Zhang et al. (2001, in brown), the 1-D-model on leaf and needle obstacles (red plain and dash) and the present model on leaf and needle obstacles (blue plain and dash). All deposition velocities are re-calculated at $z_{\mathrm{R}}=3.8 \mathrm{~m}$. The particle density is taken as $\rho_{\mathrm{p}}=1500 \mathrm{~kg} \mathrm{~m}^{-3}$.

One should notice a large dispersion within the measurements, that is not solely related to experimental uncertainty. Differences in canopy morphology (LAI, obstacle 
shape and obstacle size, $z 0 / h, d / h)$ as well as wind conditions have been proven to have a strong impact on the deposition (Davidson et al., 1982; Petroff et al., 2009, in particular Fig. 14 of the latter). The shape of the obstacle is showed here to have a significant impact on the deposition too. Let every other parameter be the same, the deposition on grass composed of plane obstacles is larger than on grass composed of cylindrical obstacles. The difference can reach a factor 3 for accumulation mode particles. The reason for such a difference is to find in the different aerodynamics around a plane obstacle and around a cylinder (within the boundary-layer and above). As a result, the deposition efficiencies associated with Brownian diffusion, interception and impaction depend strongly on the obstacle shape.

This comparison with measurements indicates reasonnable behaviours of both the leaf and the needle versions of the present model for any particle size. The model of Zhang et al. (2001) agrees with data for particle larger than some tenths of microns, but over-estimates the deposition of the smaller ones, due to its parameterization of the Brownian diffusion.

\subsection{Deposition on coniferous forests}

A similar comparison is performed on forests of different coniferous species: spruce (Beswick et al., 1991), pine (Lorenz and Murphy, 1989; Lamaud et al., 1994; Buzorius et al., 2000; Gaman et al., 2004; Grönholm et al., 2009) and fir (Gallagher et al., 1997). In these experiments, the friction velocity varies between 35 and $60 \mathrm{~cm} \mathrm{~s}^{-1}$ and the atmosphere is in a near-neutral condition. Models were fed with parameters of LUC 4 with a friction velocity of $u_{*}=47.5 \mathrm{~cm} \mathrm{~s}^{-1}$. All deposition velocities are recalculated at twice the canopy height, i.e. $z_{\mathrm{R}}=30 \mathrm{~m}$ (see Fig. 5).

Generally speaking, a good agreement is found between these measurements and the present model, though some discrepancies arise in the case of coarse fog droplets depositing on low spruce (measured by Beswick et al., 1991). The reason is that the conditions of this particular experiment are slightly different from the ones used to run the model, in particular the friction velocity is smaller $\left(u_{*}=37 \mathrm{~cm} \mathrm{~s}^{-1}\right.$ instead of $u_{*}=47.5 \mathrm{~cm} \mathrm{~s}^{-1}$ ) and the aerosol is less dense ( $\rho_{\mathrm{p}}=$ $1000 \mathrm{~kg} \mathrm{~m}^{-3}$ instead of $1500 \mathrm{~kg} \mathrm{~m}^{-3}$ ). These changes cause a lower deposition than predicted by the model in the typical coniferous situation. One can verify that by running the model with the exact parameters of Beswick et al.'s experiment (represented as a dashed blue line on Fig. 5), in which case the agreement between the model and the measurements is improved. Interestingly, the model of Zhang et al. (2001) agrees relatively well with most of these measurements, Aitken mode excepted, where it likely over-estimates the measurements by a factor 4 or more.

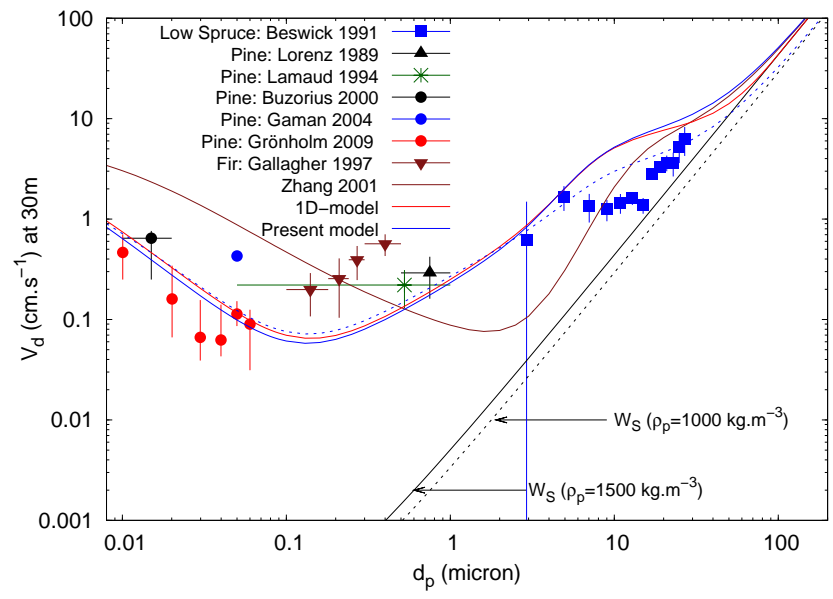

Fig. 5. Deposition on coniferous forest, as measured by Beswick et al. (1991); Lorenz and Murphy (1989); Lamaud et al. (1994); Buzorius et al. (2000); Gaman et al. (2004); Grönholm et al. (2009); Gallagher et al. (1997). A friction velocity of $47.5 \mathrm{~cm} \mathrm{~s}^{-1}$, a particle density of $1500 \mathrm{~kg} \mathrm{~m}^{-3}$ and the parameters of the LUC 4 are used to run the model of Zhang et al. (2001, in plain brown), the 1-D-model (in plain red) and the present model (in plain blue). Are added in blue dots the predictions of the present model obtained under the configuration of Beswick et al.'s experiment: $u_{*}=37 \mathrm{~cm} \mathrm{~s}^{-1}$, $h=4.2 \mathrm{~m}, h_{\mathrm{c}}=1 \mathrm{~m}, \mathrm{LAI}=10, z_{0}=0.3 \mathrm{~m}$ and $d=2.8 \mathrm{~m}, \rho_{\mathrm{p}}=$ $1000 \mathrm{~kg} \mathrm{~m}^{-3}$. All deposition velocities are re-calculated at $z_{\mathrm{R}}=$ $30 \mathrm{~m}$.

\subsection{Deposition over liquid water surfaces}

We want to estimate the ability of this simple model (Eq. 23) to reproduce measurements on liquid water surfaces. Different campaigns in wind-tunnel (Möller and Schumann, 1970; Sehmel and Sutter, 1974) and on lake (Zufall et al., 1998; Caffrey et al., 1998) are used for this purpose. The relationship between the wind and the modification of the surface morphology (waves) is accounted for according to Charnock (1955) and Smith (1988). Under neutral conditions, mean wind, friction velocity and roughness length are related by:

$z_{0}=0.11 v_{\mathrm{a}} / u_{*}+0.011 u_{*}^{2} / g$ and

$u_{*}=\kappa U\left(z_{\mathrm{R}}\right) / \ln \left(z_{\mathrm{R}} / z_{0}\right)$.

This equation is used to calculate by iteration the friction velocity and the roughness length from the wind velocity. On the Fig. 6, we present together the results of the present model and the model of Zhang et al. (2001). All deposition velocity are recalculated at $z_{\mathrm{R}}=5.2 \mathrm{~m}$ using the Eq. (10). Three wind regimes are represented on Fig. 6 with different colors: blue for low wind $\left(u_{*}=11 \mathrm{~cm} \mathrm{~s}^{-1}\right)$, red for intermediate wind $\left(u_{*}=44 \mathrm{~cm} \mathrm{~s}^{-1}\right)$, and green for strong wind $\left(u_{*}=117 \mathrm{~cm} \mathrm{~s}^{-1}\right)$.

For fine particles under the lowest wind regime, Brownian diffusion is quite inefficient to deposit particles, in which case phoretic effects are likely to dominate. Setting the value of the corresponding drift velocity to $V_{\text {phor }}=5 \times 10^{-3} \mathrm{~cm} \mathrm{~s}^{-1}$ 


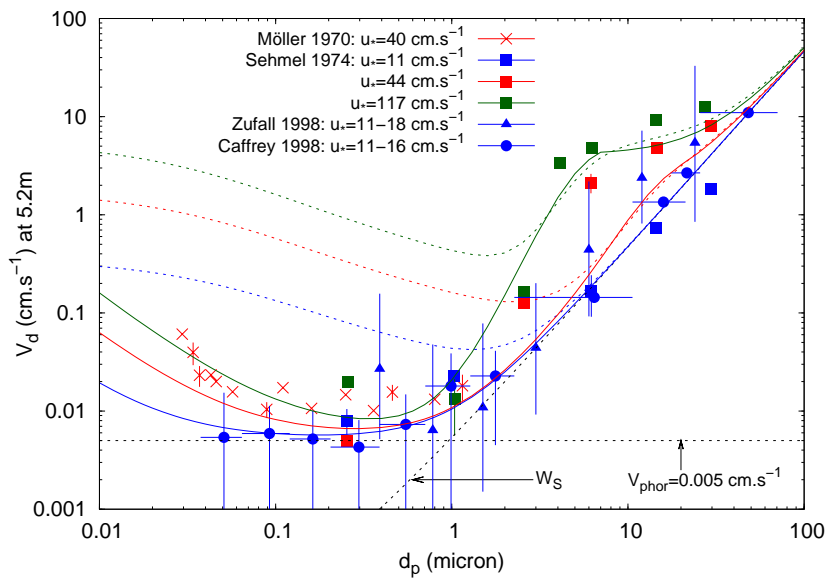

Fig. 6. Deposition on water surfaces, as measured by Möller and Schumann (1970); Sehmel and Sutter (1974); Zufall et al. (1998); Caffrey et al. (1998). The present model (plain) and the model of Zhang et al. (2001, dash) are run for $u_{*}=11 \mathrm{~cm} \mathrm{~s}^{-1}$ (blue), $u_{*}=44 \mathrm{~cm} \mathrm{~s}^{-1}$ (red) and $u_{*}=117 \mathrm{~cm} \mathrm{~s}^{-1}$ (green). All deposition velocities are re-calculated at $z_{\mathrm{R}}=5.2 \mathrm{~m}$. The particle density is taken as $\rho_{\mathrm{p}}=1500 \mathrm{~kg} \mathrm{~m}^{-3}$.

allows us to reproduce well these data. For stronger wind, the Brownian diffusion becomes efficient as the particle size decreases, which the present model is able to reproduce with a slight under-estimation (see the data of Möller and Schumann, 1970). The model of Zhang et al. (2001) significantly over-estimates the measurements for this size range, which is due to the parameterization of the Brownian diffusion efficiency (see the discussion on bare ground).

The deposition of coarser particles is driven by gravity when the wind is low and by gravity and turbulent impaction as the friction velocity increases. In most situations, a reasonable agreement is reached between the measurements and both the displayed models in low or strong winds. Some differences arise though for stronger winds and particles around $5-10 \mu \mathrm{m}$, for which an under-estimation of the present model is noticed (in most cases of a factor 2).

We emphasize that none of the measurements used in the present comparison reflects the situation of an ocean or a sea, where previous works expect an impact of spray formation on particles deposition under strong wind conditions (Williams, 1982; Hummelshøj et al., 1992; Pryor and Barthelmie, 2000). More experiments are needed to assess this effect, using preferably direct eddy-correlation measurements (see for example Norris et al., 2008).

\subsection{Deposition over snow and ice surfaces}

Snow and ice represent a significant portion of the earth surface and require to be adequately taken into account in transport models. Despite the importance of these surfaces, the direct measurements of aerosol fluxes providing as well some information about the aerosol size are sparse, relatively to

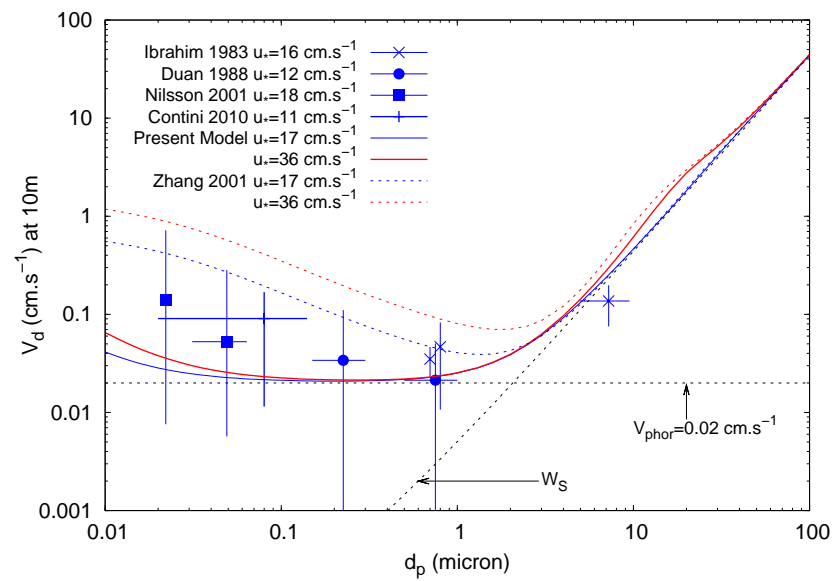

Fig. 7. Deposition on snow and ice surfaces, as measured by Ibrahim et al. (1983); Duan et al. (1988); Nilsson and Rannik (2001); Contini et al. (2010). The present model (plain) and the model of Zhang et al. (2001, dash) are run for $u_{*}=17 \mathrm{~cm} \mathrm{~s}^{-1}$ (blue) and $u_{*}=36 \mathrm{~cm} \mathrm{~s}^{-1}$ (red) for an air temperature of $273^{\circ} \mathrm{K}$ $\left(0^{\circ} \mathrm{C}\right)$ and $z_{0}=10^{-3} \mathrm{~m}$. All deposition velocities are re-calculated at $z_{\mathrm{R}}=10 \mathrm{~m}$. The particle density is taken as $\rho_{\mathrm{p}}=1500 \mathrm{~kg} \mathrm{~m}^{-3}$.

liquid water surfaces. They are obtained on snow (Ibrahim et al., 1983; Duan et al., 1988) and ice (Nilsson and Rannik, 2001; Contini et al., 2010) and the roughness length varies between $10^{-4}$ and $2 \times 10^{-2} \mathrm{~m}$ (Nilsson et al. measured roughness length up to $0.3 \mathrm{~m}-90$ percentile - over rough ice floes). The data presented here as (Contini et al., 2010) correspond to 20 near-neutral periods over which the size distribution and flux is measured simultaneously. The predictions of the present model and of the model of Zhang et al. (2001) are compared with these experiments on Fig. 7.

One should mention that the symbols and "error" bars do not represent on the Fig. 7 the same quantities. Deposition velocity is given as a mean and a standard deviation, excepted for Nilsson and Rannik (2001), for which the bar corresponds to the minimum and maximum values obtained over two unknown numbers of periods where size distributions are "typical" of ultra-fine or Aitken particles. Neither has the "error" bar on the particle diameter the same meaning in these different campaigns: Ibrahim et al. (1983) and Nilsson and Rannik (2001) do not report the meaning of these bars in their graphs. In the study of Duan et al. (1988), the bar correspond to the size bins detected by the optical counters. Finally, for the Antartica campaign of Contini et al. (2010), the bar corresponds in the present paper to the size range where $85 \%$ of the number concentration is located.

Based on these few and quite uncertain measures, the drift velocity corresponding to phoretic effects on ice and snow is chosen as $2 \times 10^{-4} \mathrm{~cm} \mathrm{~s}^{-1}$.

Agreement of these models with these measures is not really satisfactory, as the present model likely under-estimates the measures in the fine mode while Zhang et al.'s model likely over-estimates the same measurements. 
One interesting feature here is that deposition of fine particles appears to be larger over snow and ice than on water (compare with Fig. 6). In an effort to interpret their results, Ibrahim et al. (1983) invoke strong humidity gradients close to the snow ground that would affect ammonium sulfate particles and allow them to grow by hygroscopicity. The reason to explain that such behaviour would not be experienced on liquid water is unclear. Experiments over longer periods of time and with simultaneous measures of the humidity and temperature gradients close to the ground would be useful to firmly evaluate the validity of the present model on ice and snow surfaces.

\section{Conclusions and perspectives}

In the present paper, we proposed an analytical model to predict the deposition of aerosols of different sizes on the earth surface. It updates the model of Zhang et al. (2001) and depends on the morphology of the surface cover, the aerodynamics and the aerosol properties. On top of classical surface parameters like the leaf size, other factors such as the leaf shape, leaf area index and canopy height are now explicitly accounted for. This induces a larger sensitivity of the present model to changes of the land cover, compared to the earlier model (see Figs. 2 and 4). This model has been compared with measurements and gives reasonable results for bare ground (taken as a smooth surface, see Fig. 3), for different vegetation covers (short grass, see Fig. 4, and coniferous forest, see Fig. 5) and for liquid water surface (see Fig. 6). Comparatively, Zhang et al.'s model, developed at a time when measurements were sparse and incomplete, tends to adequately predict the deposition of coarse mode particles on the land covers examined in the present paper. The situation for other particle modes is more contrasted. The deposition on coniferous forest of the accumulation mode is adequately predicted while the Aitken mode measurements are over-estimated by their model. Over less rough surfaces, the deposition of fine particles is over-estimated by Zhang et al.'s model by one or two orders of magnitude. This is due to the combined limited sensitivity of their model to surface change and the parameterization of the Brownian diffusion.

Consistently with recent reviews (Pryor et al., 2008; Petroff et al., 2008a), the deposition over coniferous forest is predicted by the present model to be larger than over grass (see Fig. 2). This increase, depending on the flow and canopy properties, can reach one order of magnitude in the accumulation and coarse modes. Comparatively, the increase predicted by Zhang et al.'s model between grass and forest configuration is lower and mainly regards the coarse mode (factor of 4-5).

Based on the reviewed measurements, the minimum of deposition velocity is thought to be in the accumulation mode, which the present model is able to predict, while Zhang et al.'s model predicts it for particles around 1 or 2 microns.
In order to complete the validation of the present model, future work should focus on the influence of the stability. A simple way to account for it within the canopy has been proposed in the present study but still needs to be confronted to experimental results.

Different perspectives of improvement of this model are considered. The first regards the parameterization of the ground deposition, which in the present study is assumed to be a smooth surface. The roughness increase due to the topography and the presence of bulk obstacles like rocks or isolated plants will perturbate the flow and increase the deposition. This boundary condition needs to be improved in the future, as detailed measurements on real and rough bare ground become available.

Secondly, the phoretic effects induced by humidity and temperature gradients above solid and liquid water surfaces are described here by a simple constant drift velocity. The value of this drift velocity has been adjusted in the present study on existing measurements. As more data will become available, it should be modified or replaced by a proper paramerization. Ideally, experiments would cover particle flux and growth as well as temperature and humidity profiles close to the surface.

Thirdly, the rebound and the resuspension could be included in the future when one would be able to inform the characteristics of the deposition surface (micro-roughnesses, humidity) and the state of the aerosol and to derive simple enough formulations of these complex processes.

A fourth perspective regards processes, such as gasparticle and particle-particle interactions or particle emission, that can modify the flux balance above the canopy. Even if these processes likely are accounted for in other modules of the chemical transport model, model prediction might gain from the inclusion in the same module of all the interactions occurring between the surface and the aerosol and gas phases.

The present model is available as a open source Fortran 90 routine and can be obtained from the authors.

\section{Appendix A}

\section{Notations}

$\begin{array}{ll}C_{\mathrm{C}} & \begin{array}{l}\text { Cunningham correction fac- } \\ \text { tor } C_{\mathrm{C}}=1+2 \lambda / d_{\mathrm{p}}(1.257+\end{array} \\ & \left.0.400 e^{-1.1 d_{\mathrm{p}} /(2 \lambda)}\right) \\ & \left.\text { Brownian diffusivity } D_{\mathrm{B}}={ }^{2} \mathrm{~m}^{2} \mathrm{~s}^{-1}\right] \\ D_{\mathrm{B}} & C_{\mathrm{C}} k_{\mathrm{B}} T /\left(3 \pi \mu_{\mathrm{a}} d_{\mathrm{p}}\right) \\ E_{\mathrm{T}}, E_{\mathrm{B}}, & \begin{array}{l}\text { Deposition efficiencies on the } \\ E_{\mathrm{IN}}, E_{\mathrm{IM}}\end{array} \\ E_{\mathrm{g}} & \text { foliage } \\ & \begin{array}{l}\text { Deposition efficiency to the } \\ \text { ground }\end{array}\end{array}$




\begin{tabular}{|c|c|c|}
\hline$K_{\mathrm{p}}$ & Particle eddy diffusivity & {$\left[\mathrm{m}^{2} \mathrm{~s}^{-1}\right]$} \\
\hline$L$ & $\begin{array}{l}\text { Obstacle characteristic } \\
\text { dimension }\end{array}$ & {$[\mathrm{m}]$} \\
\hline$L_{\mathrm{O}}$ & Obhukov length & {$[\mathrm{m}]$} \\
\hline LAI & Two-side leaf area index & {$[-]$} \\
\hline$Q, Q_{\mathrm{g}}$ & $\begin{array}{l}\text { non-dimensional num- } \\
\text { bers }\end{array}$ & {$[-]$} \\
\hline$R a$ & Aerodynamic resistance & {$\left[\mathrm{s} \mathrm{m}^{-1}\right]$} \\
\hline$R e_{\mathrm{h}}$ & $\begin{array}{l}\text { Reynolds number on top } \\
\text { of the canopy }\end{array}$ & {$[-]$} \\
\hline$S c$ & Schmidt number & {$[-]$} \\
\hline$S t_{\mathrm{h}}$ & $\begin{array}{l}\text { Stokes number on top of } \\
\text { the canopy }\end{array}$ & {$[-]$} \\
\hline$T$ & $\begin{array}{l}\text { Temperature, taken as } \\
293 \text {, if not otherwise } \\
\text { stated }\end{array}$ & {$[\mathrm{K}]$} \\
\hline$U$ & $\begin{array}{l}\text { Horizontal mean flow } \\
\text { velocity }\end{array}$ & {$\left[\mathrm{m} \mathrm{s}^{-1}\right]$} \\
\hline$V_{\mathrm{d}}$ & Deposition velocity & {$\left[\mathrm{m} \mathrm{s}^{-1}\right]$} \\
\hline$V_{\text {drift }}$ & Drift velocity & {$\left[\mathrm{m} \mathrm{s}^{-1}\right]$} \\
\hline$V_{\mathrm{g}}$ & $\begin{array}{l}\text { ground deposition veloc- } \\
\text { ity }\end{array}$ & {$\left[\mathrm{m} \mathrm{s}^{-1}\right]$} \\
\hline$V_{\text {phor }}$ & phoretic drift velocity & {$\left[\mathrm{m} \mathrm{s}^{-1}\right]$} \\
\hline$V_{\mathrm{T}}$ & $\begin{array}{l}\text { total collection velocity } \\
\text { on vegetation }\end{array}$ & {$\left[\mathrm{m} \mathrm{s}^{-1}\right]$} \\
\hline$W_{\mathrm{S}}$ & $\begin{array}{l}\text { sedimentation velocity } \\
W_{\mathrm{S}}=g \tau_{\mathrm{p}}\end{array}$ & {$\left[\mathrm{m} \mathrm{s}^{-1}\right]$} \\
\hline$a$ & $\begin{array}{l}\text { Two-side leaf area den- } \\
\text { sity }\end{array}$ & {$\left[\mathrm{m}^{-1}\right]$} \\
\hline$d$ & displacement height & {$[\mathrm{m}]$} \\
\hline$d_{\mathrm{p}}$ & particle diameter & [m] \\
\hline$g$ & gravity acceleration & {$\left[\mathrm{m} \mathrm{s}^{-2}\right]$} \\
\hline$h$ & mean canopy height & {$[\mathrm{m}]$} \\
\hline$h_{\mathrm{c}}$ & $\begin{array}{l}\text { mean height of the crown } \\
\text { base }\end{array}$ & {$[\mathrm{m}]$} \\
\hline$k_{\mathrm{B}}$ & $\begin{array}{l}\text { Boltzman constant } k_{\mathrm{B}}= \\
1.38 \times 10^{-23}\end{array}$ & {$\left[\mathrm{~J} \mathrm{~K}^{-1}\right]$} \\
\hline$k_{x}$ & $\begin{array}{l}\text { inclination coefficient of } \\
\text { the canopy elements }\end{array}$ & {$[-]$} \\
\hline$l_{\mathrm{mp}}$ & $\begin{array}{l}\text { mixing length for parti- } \\
\text { cles }\end{array}$ & {$[\mathrm{m}]$} \\
\hline$u_{\mathrm{f}}$ & local friction velocity & {$\left[\mathrm{m} \mathrm{s}^{-1}\right]$} \\
\hline$u_{*}$ & friction velocity & {$\left[\mathrm{m} \mathrm{s}^{-1}\right]$} \\
\hline$z_{0}$ & roughness length & {$[\mathrm{m}]$} \\
\hline$\kappa$ & Von Kärman constant & {$[-]$} \\
\hline$\Psi_{\mathrm{m}}, \Psi_{\mathrm{h}}$ & $\begin{array}{l}\text { integrated forms of the } \\
\text { stability function for mo- } \\
\text { mentum and heat }\end{array}$ & {$[-]$} \\
\hline$\phi_{\mathrm{h}}$ & stability function for heat & {$[-]$} \\
\hline$\alpha$ & $\begin{array}{l}\text { aerodynamic extinction } \\
\text { coefficient }\end{array}$ & {$[-]$} \\
\hline$\gamma$ & $\begin{array}{l}\text { aerosol mass concentra- } \\
\text { tion density }\end{array}$ & {$\left[\mathrm{kg} \mathrm{m}^{-4}\right]$} \\
\hline$\eta$ & non-dimensional number & {$[-]$} \\
\hline$\lambda$ & $\begin{array}{l}\text { mean free path of air } \lambda= \\
0.067 \times 10^{-6}\end{array}$ & {$[\mathrm{~m}]$} \\
\hline
\end{tabular}

Geosci. Model Dev., 3, 753-769, 2010

$\begin{array}{lll}\mu_{\mathrm{a}} & \begin{array}{l}\text { air dynamic viscosity } \\ \mu_{\mathrm{a}}=1.89 \times 10^{-5}\end{array} & {\left[\mathrm{~kg} \mathrm{~m}^{-1} \mathrm{~s}^{-1}\right]} \\ & \begin{array}{l}\text { air kinematic viscosity } \\ \nu_{\mathrm{a}}\end{array} & {\left[\mathrm{m}^{2} \mathrm{~s}^{-1}\right]} \\ & \nu_{\mathrm{a}}=1.57 \times 10^{-5} & \\ \tau_{\mathrm{p}}^{+} & \text {non-dimensional particle } & {[-]} \\ & \text { relaxation time } & \\ \tau_{\mathrm{p}} & \begin{array}{l}\text { particle relaxation time } \\ \tau_{\mathrm{p}}=C_{\mathrm{C}} \rho_{\mathrm{p}} d_{\mathrm{p}}^{2} /\left(18 \mu_{\mathrm{a}}\right)\end{array} & {[\mathrm{s}]} \\ \rho_{\mathrm{p}} & \text { particle density } & {\left[\mathrm{kg} \mathrm{m}^{-3}\right]}\end{array}$

Acknowledgements. Daniele Contini is acknowledged for sharing with us the aerosol data obtained in Antartica.

Edited by: R. Sander

\section{References}

Andersson, C., Langner, J., and Bergström, R.: Interannual variation and trends in air pollution over Europe due to climate variability during 1958-2001 simulated with a regional CTM coupled to the ERA40 reanalysis, Tellus, 59B, 77-98, 2007.

Bache, D.: Particle transport within plant canopies. I. A framework for analysis, Atmos. Environ., 13, 1257-1262, 1979.

Batchelor, G. and Shen, C.: Thermophoretic deposition in gas flow over cold surfaces, Journal of Colloid Interface Science, 107, 21 37, 1985.

Bessagnet, B., Hodzic, A., Vautard, R., Beekmann, M., Cheinet, S., Honoré, C., Liousse, C., and Rouil, L.: Aerosol modelling with CHIMERE-preliminary evaluation at the continental scale, Atmos. Environ., 38, 2803-2817, 2004.

Beswick, K., Hargreaves, K., Gallagher, M., Choularton, T., and Fowler, D.: Size-resolved measurements of cloud droplet deposition velocity to a canopy using an eddy correlation technique, Q. J. Roy. Meteorol. Soc., 117, 623-645, 1991.

Brunet, Y., Finnigan, J., and Raupach, M.: A wind Tunnel study of Air Flow in Waving Wheat: Single point velocity statistics, Bound.-Lay. Meteorol., 70, 95-132, 1994.

Buzorius, G., Rannik, Ü., Mäkelä, J., Vesala, T., and Kulmala, M.: Vertical aerosol fluxes measured by eddy covariance methods and deposition of nucleation mode particles above a Scots pine forest in southern Finland, J. Geophys. Res., 105, 19905-19916, 2000.

Caffrey, P., Ondov, J., Zufall, M., and Davidson, C.: Determination of size-dependent dry particle deposition velocities with multiple intrisic elemental tracers, Environ. Sci. Technol., 32, 1615-1622, 1998.

Cellier, P. and Brunet, Y.: Flux-gradient relationships above tall plant canopies, Agr. Forest Meteorol., 58, 93-117, 1992.

Chamberlain, A.: Transport of Lycopodium spores and other small particles to rough surfaces, Proceedings of the Royal Society London, 296, 45-70, 1967.

Charnock, H.: Wind stress on a water surface, Q. J. Roy. Meteorol. Soc., 81, 639-640, 1955.

Clough, W.: The deposit of particles on moss and grass surfaces, Atmos. Environ., 9, 1113-1119, 1975.

Contini, D., Donateo, A., Belosi, F., Grasso, F., Santachiara, G., and Prodi, F.: Deposition velocity of ultrafine particles measured with the eddy-correlation method over the 
Nansen Ice Sheet (Antartica), J. Geophys. Res., 115, D16202, doi:10.1029/2009JD013600, 2010.

Côté, J., Gravel, S., Méthot, A., Patoine, A., Roch, M., and Staniforth, A.: The operational CMC-MRB Global Environmental Multiscale (GEM) model. Part I: Design considerations and formulation, Mon. Weather Rev., 126, 1373-1395, 1998.

Davidson, C., Miller, J., and Pleskow, M.: The influence of surface structure on predicted particle dry deposition to natural grass canopies, Water, Air and Soil Pollution, 18, 25-43, 1982.

Davies, C.: Deposition from moving aerosols, in: Aerosol science, edited by Davies, C. N., pp. 393-446, Academic Press, London, UK, 1966

Denmead, O. and Bradley, E.: Flux-gradient relationships in a forest canopy, in: The Forest-Atmosphere Interaction, edited by: Hutchinson, B. and Hicks, B. B., pp. 421-442, D. Reidel Publishing Company, Dordrecht, 1985.

Dickinson, R. E., Henderson-Sellers, A., Kennedy, P. J., and Wilson, M. F.: Biosphere-Atmosphere Transfer Scheme (BATS) for the NCAR Community Climate Model, Tech. Rep. NCAR/TN275+STR, National Centre for Atmospheric Research, Boulder, Colorado, 1986.

Dorsey, J., Nemitz, E., Gallagher, M.W. Fowler, D., Williams, P., Bower, K., and Beswick, K.: Direct measurements and parameterisation of aerosol flux, concentration and emission velocity above a city, Atmos. Environ., 36, 791-800, 2002.

Duan, B., Fairall, C., and Thomson, D.: Eddy-correlation measurements of the dry deposition of particles in wintertime, J. Appl. Meteorol., 27, 642-652, 1988.

Dyer, A.: A review of flux-profile relationships, Bound.-Lay. Meteorol., 7, 363-372, 1974.

Englert, N.: Fine particles and human health - a review of epidemiological studies, Toxicol. Lett., 149, 235-242, 2004.

Erisman, J., Hensen, A., Fowler, D., Flechard, C., Grüner, A., Spindler, G., Duyzer, J., Weststrate, H., Römer, F., Vonk, A., and Jaarsveld, H.: Dry deposition monitoring in Europe, Water, Air and Soil Pollution: Focus, 1, 17-27, 2001.

Fazu, C. and Schwerdtfeger, P.: Flux-gradient relationships for momentum and heat over a rough natural surface, Q. J. Roy. Meteorol. Soc., 115, 335-352, 1989.

Fernandez de la Mora, F. and Friedlander, S.: Aerosol and gaz deposition of particles to fully rough surfaces, Int. J. Heat Mass Tran., 26, 1725-1735, 1982.

Fitzgerald, J.: Approximation formulas for equilibrium size of an aerosol particle as a function of its dry size and composition and ambient relative humidity, J. Appl. Meteorol., 14, 1044-1049, 1975.

Fowler, D., Pilegaard, K., Sutton, M. A., Ambus, P., Raivonen, M., Duyzer, J., Simpson, D., Fagerli, H., Fuzzi, S., Schjoerring, J. K., Granier, C., Neftel, A., Isaksen, I. S. A., Laj, P., Maione, M., Monks, P. S., Burkhardt, J., Daemmgen, U., Neirynck, J., Personne, E., Wichink-Kruit, R., Butterbach-Bahl, K., Flechard, C., Tuovinen, J. P., Coyle, M., Gerosa, G., Loubet, B., Altimir, N., Gruenhage, L., Ammann, C., Cieslik, S., Paoletti, E., Mikkelsen, T. N., Ro-Poulsen, H., Cellier, P., Cape, J. N., Horvath, L., Loreto, F., Niinemets, U., Palmer, P. I., Rinne, J., Misztal, P., Nemitz, E., Nilsson, D., Pryor, S., Gallagher, M. W., Vesala, T., Skiba, U., Brueggemann, N., Zechmeister-Boltenstern, S., Williams, J., O'Dowd, C., Facchini, M. C., de Leeuw, G., Flossman, A., Chaumerliac, N., and Erisman, J. W.: Atmospheric composition change: Ecosystems-Atmosphere interactions, Atmos. Environ., 43, 5193-5267, 2009.

Gallagher, W., Choularton, T., Morse, A., and Fowler, D.: Measurements of the size dependence of cloud droplet deposition at a hill site, Q. J. Roy. Meteorol. Soc., 114, 1291-1303, 1988.

Gallagher, M., Beswick, K., Duyzer, J., Westrate, H., Choularton, T., and Hummelshøj, P.: Measurements of aerosol fluxes to Speulder forest using a micrometeorological technique, Atmos. Environ., 31, 359-373, 1997.

Gaman, A., Rannik, Ü., Aalto, P., Pohja, T., Siivola, E., Kulmala, M., and Vesala, T.: Relaxed eddy accumulation system for size resolved aerosol particle flux measurements, J. Atmos. Oceanic Technol., 21, 933-943, 2004.

Garland, J.: Dry deposition of small particles to grass in field conditions, in: Precipitation scavenging, dry deposition and resuspension, edited by: Pruppacher, H., Semonin, R., and Slinn, W., vol. 2, pp. 849-857, Elsevier, Amsterdam, Nederlands, 1983.

Gerber, H.: Relative-humidity parameterization of the Navy aerosol model (NAM), in: NRL Report 8956, National Research Laboratory, Washington D.C., 1985.

Ghan, S. J. and Easter, R. C.: Impact of cloud-borne aerosol representation on aerosol direct and indirect effects, Atmos. Chem. Phys., 6, 4163-4174, doi:10.5194/acp-6-4163-2006, 2006.

Gillette, D., Lawson Jr., R., and Thompson, R.: A "test of concept" comparison of aerodynamic and mechanical resuspension mechanisms for particles deposited on field rye grass (Secale cercele). - Part 2. Threshold mechanical energies for resuspension particle fluxes, Atmos. Environ., 38, 4799-4803, 2004.

Giorgi, F.: A particle dry deposition parameterisation scheme for use in tracer transport models, J. Geophys. Res., 91, 9794-9806, 1986.

Goldsmith, P. and May, F.: Diffusiophoresis and thermophoresis in water vapour systems, in: Aerosol science, edited by: Davies, C. N., pp. 163-194, Academic Press, London, UK., 1966.

Gong, S., Barrie, L., Blanchet, J.-P., von Salzen, K., Lohmann, U., Lesins, G., Spacek, L., Zhang, L., Lin, H., Leaitch, R., Leighton, H., Chylek, P., and Huang, S.: Canadian aerosol module: a sizesegretated simulation of atmospheric aerosol processes for climate and air quality models. 1. Model development, J. Geophys. Res., 108, 4007, doi:10.1029/2001JD002002, 2003.

Gong, W., Dastoor, A., Bouchet, V., Gong, S., Makar, P., Moran, M., Pabla, B., Ménard, S., Crevier, L.-P., Cousineau, S., and Venkatesh, S.: Cloud processing of gases and aerosols in a regional air quality model (AURAMS), Atmos. Res., 82, 248-275, 2006.

Grönholm, T., Launiainen, S., Ahlm, L., Mårtensson, E., Kulmala, M., Vesala, T., and Nilsson, E.: Aerosol particle dry deposition to canopy and forest floor measured by two-layer eddy covariance system, J. Geophys. Res., 114, D04202, doi:10.1029/2008JD010663, 2009.

Hansen, M., Defries, R., Townshend, J., and Sohlberg, R.: Global land cover classification at $1 \mathrm{~km}$ spatial resolution using a classification tree approach, Int. J. Remote Sens., 6, 1331-1364, 2000.

Harman, I. and Finnigan, J.: A simple unified theory for flow in the canopy and roughness sublayer, Bound.-Lay. Meteorol., 123, 339-363, 2007.

Heald, C., Jacob, D., Park, R., Alexander, B., Fairlie, T. D., Yantosca, R., and Chu, D. A.: Transpacific transport of Asian anthropogenic aerosols and its impact on surface air qual- 
ity in the United States, J. Geophys. Res., 111, D14310, doi:10.1029/2005JD006847, 2006.

Hummelshøj, P., Jensen, N. O., and Larsen, S. E.: Particle dry deposition to a Sea Surface, in: Fifth International Conference on Precipitation Scavenging and Atmosphere-Surface Exchange Processes, AMS, Richland, Washington, USA, 1992.

Ibrahim, M., Barrie, L., and Fanaki, F.: An experimental and theoretical investigation of the dry deposition of particles to snow, pine trees and artificial collectors, Atmos. Environ., 17, 781-788, 1983.

Inoue, E.: On the turbulent structure of airflow within crop canopies, Journal of Agricultural and Meteorological Society of Japan, 11, 18-22, 1963.

IPCC: Climate Change 2007: The Physical Science Basis. Contribution of Working Group I to the Fourth Assessment Report of the Intergovernmental Panel on Climate Change, Cambridge University Press, Cambridge, United Kingdom and New York, NY, USA, 2007.

Jarosz, N., Loubet, B., and Huber, L.: Modelling airborne concentration and deposition rate of maize pollen, Atmos. Environ., 38, 5555-5566, 2004.

Kaimal, J. and Finnigan, J.: Flow over plant canopies, in: Atmospheric Boundary Layer Flows, Oxford University Press, New York, USA, 1994.

Kappos, A., Bruckmann, P., Eikmann, T., Englert, N., Heinrich, U., Hoppe, P., Koch, E., Krause, G., Kreyling, W., Rauchfuss, K., Rombout, P., Schulz-Klemp, V., Thiel, W., and Wichmann, H.: Health effects of particles in ambient air, Int. J. Hyg. Envir. Heal., 207, 399-407, 2004.

Lamaud, E., Brunet, Y., Labatut, A., Lopez, A., Fontan, J., and Druilhet, A.: The Landes Experiment: Biosphere-atmosphere exchanges of ozone and aerosol particles above a pine forest, J. Geophys. Res., 99, 16511-16521, 1994.

Leclerc, M., Shaw, R., Den Hartog, G., and Neumann, H.: The influence of atmospheric stability on the budgets of the Reynolds stress and turbulent kinetic energy within and above a deciduous forest, J. Appl. Meteorol., 29, 916-933, 1990.

Lee, K. and Liu, B.: Experimental study of aerosol filtration by fibrous filters, Aerosol Sci. Technol., 1, 35-46, 1982.

Lee, Y. and Mahrt, L.: Effect of stability on mixing in open canopies, Agr. Forest Meteorol., 135, 169-179, 2005.

Lippmann, M., Frampton, M., Schwartz, J., Dockery, D., Schlesinger, R., Koutrakis, P., Froines, J., Nel, A., Finkelstein, J., Godleski, J., Kaufman, J., Koenig, J., Larson, T., Luchtel, D., Liu, L., Oberdorster, G., Peters, A., Sarnat, J., Sioutas, C., Suh, H., Sullivan, J., Utell, M., Wichmann, E., and Zelikoff, J.: The US Environmental Protection Agency particulate matter health effects research centers program: A midcourse report of status, progress, and plans, Environ. Health Persp., 111, 1074-1092, 2003.

Lorenz, R. and Murphy, J.: Dry deposition of particles to a pine plantation, Bound.-Lay. Meteorol., 46, 355-366, 1989.

Loveland, T. and Belward, A.: The IGBP-DIS global $1 \mathrm{~km}$ land cover data set, DISCover: first results, Int. J. Remote Sens., 18, 3289-3295, 1997.

Mårtensson, E. M., Nilsson, E. D., Buzorius, G., and Johansson, C.: Eddy covariance measurements and parameterisation of traffic related particle emissions in an urban environment, Atmos. Chem. Phys., 6, 769-785, doi:10.5194/acp-6-769-2006, 2006.
McMahon, T. and Denison, P.: Empirical atmospheric deposition a survey, Atmos. Environ., 13, 571-585, 1979.

Möller, U. and Schumann, G.: Mechanisms of transport from the atmosphere to the earth's surface, J. Geophys. Res., 75, 30143019, 1970.

Monin, A. and Obhukov, A.: Basic laws of turbulent mixing in the ground layer of the atmosphere, Akademiia Nauk SSSR, Leningrad, Geofizicheskii Institut, Trudy, and translated by the AMS, 24, 163-187, 1954.

Nemitz, E. and Sutton, M. A.: Gas-particle interactions above a Dutch heathland: III. Modelling the influence of the NH3HNO3-NH4NO3 equilibrium on size-segregated particle fluxes, Atmos. Chem. Phys., 4, 1025-1045, doi:10.5194/acp-4-10252004, 2004.

Nemitz, E., Gallagher, M., Duyzer, J., and Fowler, D.: Micrometeorological measurements of particle deposition velocities to moorland vegetation, Q. J. Roy. Meteorol. Soc., 128, 2281-2300, 2002.

Nemitz, E., Dorsey, J. R., Flynn, M. J., Gallagher, M. W., Hensen, A., Erisman, J.-W., Owen, S. M., Dämmgen, U., and Sutton, M. A.: Aerosol fluxes and particle growth above managed grassland, Biogeosciences, 6, 1627-1645, doi:10.5194/bg-6-16272009, 2009.

Nho-Kim, E.-Y., Michou, M., and Peuch, V.-H.: Parametrization of size-dependent particle dry deposition velocity for global modeling, Atmos. Environ., 38, 1933-1942, 2004.

Nilsson, E. and Rannik, Ü.: Turbulent aerosol fluxes over the Arctic Ocean 1. Dry deposition over sea and pack ice, J. Geophys. Res.Atmos., 106, 32125-32137, 2001.

Norris, S. J., Brooks, I. M., de Leeuw, G., Smith, M. H., Moerman, M., and Lingard, J. J. N.: Eddy covariance measurements of sea spray particles over the Atlantic Ocean, Atmos. Chem. Phys., 8, 555-563, doi:10.5194/acp-8-555-2008, 2008.

Papavergos, P. and Hedley, A.: Particle deposition behaviour from turbulent flows, Chemical Engineering Research and Design, 62, 275-293, 1984.

Paulson, C.: The mathematical representation of wind speed and temperature profiles in the unstable atmospheric surface layer, $\mathrm{J}$. Appl. Meteorol., 9, 857-861, 1970.

Paw U, K.: The rebound of particles from natural surfaces, Journal of colloid Interface Science, 93, 442-452, 1983.

Paw U, K. and Braaten, D.: Experimental Evidence of the importance of rebound in net deposition of particles, Aerosol Sci. Technol., 17, 278-288, 1992.

Petroff, A.: Mechanistic study of aerosol dry deposition on vegetated canopies, Phd thesis, University of Aix-Marseille II, available in French at http://tel.archives-ouvertes.fr/tel-00011658/en/, 2005.

Petroff, A., Mailliat, A., Amielh, M., and Anselmet, F.: Aerosol dry deposition on vegetative canopies. Part I: Review of present knowledge, Atmos. Environ., 42, 3625-3653, 2008a.

Petroff, A., Mailliat, A., Amielh, M., and Anselmet, F.: Aerosol dry deposition on vegetative canopies. Part II: A new modeling approach and applications, Atmos. Environ., 42, 3654-3683, 2008 b.

Petroff, A., Zhang, L., Pryor, S., and Belot, Y.: An extended dry deposition model for aerosols onto broadleaf canopies, J. Aerosol Sci., 40, 218-240, 2009.

Pryor, S. and Barthelmie, R.: Particle dry deposition to water sur- 
faces: Processes and consequences, Mar. Pollut. Bull., 41, 220231, 2000.

Pryor, S. and Binkowski, F.: An analysis of the time scales associated with aerosol processes during dry deposition, Aerosol Sci. Technol., 38, 1091-1098, 2004.

Pryor, S., Larsen, S., Sørensen, L., Barthelmie, R., Grönholm, T., Kulmala, M., Launiainen, S., Rannik, Ü., and Vesala, T.: Particle fluxes over forests: Analyses of flux methods and functional dependencies, J. Geophys. Res., 112, D07205, doi:10.1029/2006JD008066, 2007.

Pryor, S., Gallagher, M., Sievering, H., Larsen, S., Barthelmie, R., Birsan, F., Nemitz, E., Rinne, J., Kulmala, M., Grönholm, T., Taipale, R., and Vesala, T.: A review of measurement and modelling results of particle atmosphere-surface exchange, Tellus B, 60, 42-75, 2008.

Raes, F., Van Dingenen, R., Vignati, E., Wilson, J., Putaud, J.-P., Seinfeld, J., and Adams, P.: Formation and cycling of aerosols in the global troposphere, Atmos. Environ., 34, 4215-4240, 2000.

Raupach, M.: Simplified expressions for vegetation roughness length and zero-plane displacement as functions of canopy height and area index, Bound.-Lay. Meteorol,, 71, 211-216, 1994.

Raupach, M.: Corrigenda - Simplified expressions for vegetation roughness length and zero-plane displacement as functions of canopy height and area index, Bound.-Lay. Meteorol., 76, 303304, 1995.

Raupach, M., Antonia, R., and Rajagopalan, S.: Rough-wall turbulent boundary layers, Appl. Mechanics Rev., 44, 1-24, 1991.

Ruijgrok, W., Davidson, C., and Nicholson, K.: Dry deposition of particles. Implications and recommendations for mapping of deposition over Europe, Tellus, 47B, 587-601, 1995.

Schmidt, A. and Klemm, O.: Direct determination of highly sizeresolved turbulent particle fluxes with the disjunct eddy covariance method and a 12-stage electrical low pressure impactor, Atmos. Chem. Phys., 8, 7405-7417, doi:10.5194/acp-8-7405-2008, 2008.

Sehmel, G.: Particle eddy diffusivity and deposition velocities for isothermal flow and smooth surfaces, J. Aerosol Sci., 4, 125-138, 1973.

Sehmel, G. and Hodgson, W.: A model for predicting dry deposition of particles and gases to environmental surfaces, Tech. Rep. PNL-SA-6721, Battelle, Pacific Northwest Laboratories, 1978.

Sehmel, G. and Sutter, S.: Particle deposition rates on a water surface as a function of particle diameter and air velocity, Journal de recherches atmosphériques, 8, 911-920, 1974.

Slinn, W.: Prediction for particle deposition to vegetative canopies, Atmos. Environ., 16, 1785-1794, 1982.

Smith, S.: Coefficients for sea surface wind Stress, heat Flux, and wind profiles as a function of wind speed and temperature, J. Geophys. Res., 92, 15467-15472, 1988.

Tammet, H., Kimmel, V., and Israelsson, S.: Effect of atmospheric electricity on dry deposition of airborne particles from atmosphere, Atmos. Environ., 35, 3413-3419, 2001.

Textor, C., Schulz, M., Guibert, S., Kinne, S., Balkanski, Y., Bauer, S., Berntsen, T., Berglen, T., Boucher, O., Chin, M., Dentener, F., Diehl, T., Easter, R., Feichter, H., Fillmore, D., Ghan, S., Ginoux, P., Gong, S., Grini, A., Hendricks, J., Horowitz, L., Huang, P., Isaksen, I., Iversen, I., Kloster, S., Koch, D., Kirkevåg, A., Kristjansson, J. E., Krol, M., Lauer, A., Lamarque, J. F., Liu, X., Montanaro, V., Myhre, G., Penner, J., Pitari, G., Reddy, S.,
Seland, Ø., Stier, P., Takemura, T., and Tie, X.: Analysis and quantification of the diversities of aerosol life cycles within AeroCom, Atmos. Chem. Phys., 6, 1777-1813, doi:10.5194/acp-61777-2006, 2006.

Waldman, L. and Schmitt, K.: Thermophoresis and diffusiophoresis of aerosols, in: Aerosol science, edited by: Davies, C. N., pp. 137-162, Academic Press, London, UK, 1966.

Wang, Z., Li, J., Wang, X., Pochanart, P., and Akimoto, H.: Modeling of Regional High Ozone Episode Observed at Two Mountain Sites (Mt. Tai and Huang) in East China, J. Atmos. Chem., 55, 253-272, 2006.

Williams, R.: A model for the dry deposition of particles to naturalwater surfaces, Atmos. Environ., 16, 1933-1938, 1982.

Williams, J., de Reus, M., Krejci, R., Fischer, H., and Ström, J.: Application of the variability-size relationship to atmospheric aerosol studies: estimating aerosol lifetimes and ages, Atmos. Chem. Phys., 2, 133-145, doi:10.5194/acp-2-133-2002, 2002.

Wilson, M. and Henderson-Sellers, A.: A global archive of land cover and soils data for use in general circulation climate models, J. Climatol., 5, 119-143, 1985.

Wood, N.: A simple method for the calculation of turbulent deposition to smooth and rough surfaces, J. Aerosol Sci., 12, 275-290, 1981.

Wu, Y., Davidson, C., and Russell, A.: Controlled wind-tunnel experiments for particle bounceoff and resuspension, Aerosol Sci. Technol., 17, 245-262, 1992a.

Wu, Y., Davidson, C., and Russell, A.: A stochastic-model for particle deposition and bounceoff, Aerosol Sci. Technol., 17, 231244, 1992b.

Yoshioka, N., Emi, H., Kanaoka, C., and Yasunami, M.: Efficiency of aerosol trapping by an isolated cylinder : gravity and inertia dominant regions, Kagaku Kagaku, 36, 313-319, 1972.

Zakey, A. S., Solmon, F., and Giorgi, F.: Implementation and testing of a desert dust module in a regional climate model, Atmos. Chem. Phys., 6, 4687-4704, doi:10.5194/acp-6-4687-2006, 2006.

Zhang, K., Knipping, E., Wexler, A., Bhave, P., and Tonnesen, G.: Size distribution of sea-salt emissions as a function of relative humidity, Atmos. Environ., 39, 3373-3379, 2005.

Zhang, L. and Vet, R.: A review of current knowledge concerning size-dependent aerosol removal, China Particuology, 4, 272-282, 2006.

Zhang, L., Gong, S., Padro, J., and Barrie, L.: A size-segregated particle dry deposition scheme for an atmospheric aerosol module, Atmos. Environ., 35, 549-560, 2001.

Zhang, L., Brook, J. R., and Vet, R.: A revised parameterization for gaseous dry deposition in air-quality models, Atmos. Chem. Phys., 3, 2067-2082, doi:10.5194/acp-3-2067-2003, 2003.

Zhao, T., Gong, S., Zhang, X., and McKendry, I.: Modeled sizesegregated wet and dry deposition budgets of soil dust aerosol during ACE-Asia 2001: Implications for trans-Pacific transport, J. Geophys. Res., 108, D238665, doi:10.1029/2002JD003363, 2003.

Zufall, M., Davidson, C., Caffrey, P., and Ondov, J.: Airborne concentration and dry deposition fluxes of particulate species to surrogate surfaces deployed in southern Lake Michigan, Environ. Sci. Technol., 32, 1623-1628, 1998. 